\begin{tabular}{|c|l|}
\hline Title & A Descriptive Statistics on Coworking Spaces in Japan \\
\hline Author(s) & Uda, Tadashi; A be, Tomokazu \\
\hline Citation & Discussion Paper, Series A, 297, 1-40 \\
\hline Issue Date & 2015-12 \\
\hline Doc URL & http://hdl.handle.net/2115/60456 \\
\hline Type & bulletin (article) \\
\hline File Information & DPA 297new.pdf \\
\hline
\end{tabular}

Instructions for use 
Discussion Paper, Series A, No.2015-297

\section{A Descriptive Statistics on Coworking Spaces \\ in Japan}

Tadashi Uda and Tomokazu Abe

December.2015

Graduate School of Economics \&

Business Administration

Hokkaido University

Kita 9 Nishi 7, Kita-Ku, Sapporo 060-0809, JAPAN 


\title{
A Descriptive Statistics on Coworking Spaces in Japan
}

\author{
Tadashi Uda and Tomokazu Abe \\ Graduate School of Economics and Business Administration, Hokkaido University
}

\begin{abstract}
This paper aims to shed light on the actual condition of coworking spaces in Japan based on a questionnaire survey. A way of working called "coworking” and a place for such work called "coworking space" have been attracting attention in recent years because they may provide a more flexible work style, diverse members to interact with, and open spaces than are experienced when working in a specific company or corporate office. However, the understanding of this phenomenon is insufficient. Therefore, in this paper we will first review coworking studies with a focus on the annual Global Coworking Survey conducted around the world. Then, we will present the results of the descriptive statistics of a questionnaire survey conducted among almost all coworking spaces operating in Japan from six perspectives: facility, management organization, business strategy, activity, space users, and performance. Based on the results, we will then present and examine the findings of this paper.
\end{abstract}

Keywords: Coworking, Coworking Space, Descriptive Statistics, Complete Enumeration 


\section{Introduction}

This paper aims to shed light on the current status of coworking space in Japan based on a questionnaire survey. Specifically, we conduct an online survey, analyze the data obtained from 152 out of 365 spaces - nearly all the operating facilities in Japan (as of July 2014) —and show the results of the descriptive statistics relating to the current status of those spaces from six perspectives: facility, management organization, business strategy, activity, space users, and performance.

The term "coworking" refers to a "way of working in which individual workers gather in a place, share information and wisdom through communication, and create value while cooperating as needed" (Uda, 2013), and "coworking space” refers to a workspace physically shared by individuals practicing coworking.

This way of working and its spaces have been attracting attention because they may be able to provide a more flexible work style, diverse members to interact with, and open spaces than are possible for those working in a company or corporate office. Coworking spaces have been established one after another in many countries, running to approximately $7,800^{1}$ worldwide and more than 350 in Japan today. However, the current understanding of coworking and coworking spaces is insufficient. Therefore, this paper shows the actual condition of coworking spaces in Japan based on a questionnaire survey, in order to contribute researchers in related fields, space managers of coworking spaces, and those attempting to enter the industry.

The rest of this paper is structured as follows. Section 2 reveiws previous studies on coworking. Section 3 explains the method used in this paper. Section 4 describes the results of an analysis of the data collected using the method described in Section 3. Section 5 examines the analysis results presented in Section 4. Section 6 summarizes the discussion up to Section 5, presents the significance of this paper, and suggests future research issues.

\section{Previous Studies}

\subsection{Theoretical Trends on Coworking}

It is said that the way of work called "coworking” and its work space, called "coworking space," began when Brad Neuberg, who was working as a freelance engineer, opened the space at Spiral Muse in San Francisco on August 9, 2005 and began working with his friends. ${ }^{2}$ Afterwards, similar attempts were made in the United States, primarily in large cities, as well as in Europe and other regions. As a result, close to 7,800 spaces worldwide-mainly in the United States and Europe-are in operation and are used by approximately 300,000 people ${ }^{3}$, as described earlier.

\footnotetext{
1 See the facebook page of Deskmag:

(https://www.facebook.com/deskmag.coworking/photos/a.208558519173827.61310.186275991402080/1166979896 665013/?type=3\&theater). Deskmag, an online magazine about coworking, conducts the Global Coworking Survey described later.

2 See the website on the history of coworking presented by Deskmag: (http://www.tiki-toki.com/timeline/entry/156192/The-History-Of-Coworking-Presented-By-Deskmag/\#vars!panel=1 505040 ! ). For details on the development of the phenomenon of coworking, see Uda (2013) and Hanibuchi (2014).

3 See Deskmag's article of December 19, 2014:

(http://www.deskmag.com/en/these-major-coworking-conferences-events-barcamps-will-take-place-in-2015 ).
} 
More than 350 facilities have been offering the service in Japan since Tomio Ito opened Cahootz in Kobe in 2010, merely five years ago.

Thus, the phenomenon of coworking and coworking space is steadily spreading not only in the United States and Europe but also in Japan and other countries. As a result, various media are discussing the history, current state, and outlook of coworking. However, very few studies have empirically examined the actual condition of coworking or coworking space.

Needless to say, suggestive findings are being accumulated in Japan and overseas, albeit gradually. For example, Spinuzzi (2012) focused on nine coworking spaces located in Austin, Texas and attempted to explain the three research questions of "what is coworking," "who coworks," and "why do people cowork" based on interviews with 16 space managers and 17 users. As a result, the facts as follows were ascertained. Firstly, while space manager's definition of "coworking” can be summed up as "community work space," "unoffice," or "federated spaces," the users' definitions — such as "alternative office space” or "social hub" - tend to be diverse and differ from those of space managers. Secondly, although space managers expected users who shared their own backgrounds, the users actually worked in a various industries and capacities. Lastly, users expect to get things like good locations and partnerships between users, and interaction.

Meanwhile, directing our attention to Japan, Arimoto, Matsumoto, Matsumoto, Kidosaki, and Naka (2012), classified spaces in Japan based on secondary sources and summarized the work styles of seven users based on a diary survey and interviews in an attempt to understand the current state of coworking. The results indicated that the 54 coworking spaces verified at the time of the study could be grouped into five categories-independent type (48\%), cafe/bar type (17\%), corporate in-house type (5\%), shared office type (17\%), and other (13\%)—based on their characteristics. The results also showed tendencies such as "spaces are likely to be used from early afternoon to early evening."

In addition, Watanabe, Matsumoto, Matsumoto, Kidosaki, and Naka (2012) used data collected from 40 users through an online survey and examined factors that influenced them when choosing a space. The results showed that being available for use at all times as well as factors such as specialty and personality of the owner affected the choice of space.

Furthermore, after summarizing and examining the status of 23 spaces in Japan, Nakamura (2013) attempted to classify the spaces on two axes: the purpose of operation (specific purpose-oriented vs. community-oriented) and the style of use (drop-in style vs. tenant style). The results showed that coworking spaces are evolving from the drop-in/community-oriented type to the tenant/specific purpose-oriented type. It also presented seven space operation issues, such as the method of community formation in the space and the development of profit-generation systems.

Most of the research in Japan is being pursued in fields such as architecture and business management. Particularly worth noting is Hanibuchi (2014), which systematically and empirically examined coworking and coworking space. After clarifying the actual condition of coworking space as a place to work together, Hanibuchi discusses the effect that those spaces have on people's social relationships as well as cities and regions. Specifically, he describes the current status of the operation and usage of the spaces based on interviews with space managers as well as a survey and 
interviews conducted among users, ${ }^{4}$ discusses the analysis results, and makes policy recommendations by citing social capital as well as the creative city theory. In terms of space operation, the results showed that space managers value community formation and the diversity of members, face more difficulties in operating a space than in opening a space, and are more conscious of their relationship with the government in rural areas than they are in urban areas. Meanwhile, in terms of the usage of space, numerous suggestive findings have been presented, such as the fact that primary users tend to be in their 30s (46.4\%), male (82.8\%), in professional or technical fields (e.g., engineers, software developers; 51\%), and freelancers (46.9\%).

However, there might be a certain regional bias in the data Hanibuchi relied on, which were collected mainly from spaces located in Nagoya and special districts in Tokyo as well as from their users. Therefore, the findings are unlikely to be fully in line with the actual condition of coworking and coworking spaces in Japan.

In addition, the other aforementioned Japanese studies are based on surveys with limited scopes or limited target populations and thus do not present a clear picture of this phenomenon. ${ }^{5}$

Under these circumstances, the Global Coworking Survey (GCS), conducted annually since 2010 by Deskmag, is a very valuable information source for understanding the overall picture and its changes on a global scale. Therefore, we will review the findings of the GCS in the next section.

\subsection{Global Coworking Survey}

The GCS is an annual survey on coworking conducted globally by Deskmag. The purpose of this survey is to describe the state of coworking spaces themselves, their users, space managers, and potential users.

The first survey, conducted in December 2010, collected data from 661 individuals in 24 countries. The second survey was conducted from October to November 2011 and, though using fewer questions than the first survey, collected data from more than 1,500 individuals in 52 countries. The third survey was conducted between October and November 2012 and collected data from 2,007 individuals. The fourth survey, conducted from November to December 2013, collected data from 2,706 individuals. The fifth survey was completed in December 2014.

Here, we will focus on the first through third surveys, which published summary reports, and discuss them from six perspectives: facility, management organization, business strategy, activity, space users, and performance. By focusing on these, we should be able to comprehensively understand the current state of coworking space.

\footnotetext{
${ }^{4}$ Specifically, interviews with 11 space managers (including five in Nagoya, three in special districts in Tokyo, and three in other regional cities), a survey among users at five spaces (including two locations in Nagoya, one location in a special district in Tokyo, and two locations in other regional cities), and interviews with five users (in Nagoya) were conducted.

5 Other studies on coworking include studies such as Kobayashi (2011), which discussed the establishment of the library as a coworking space (it mentions that people were practicing the idea before the concept of coworking emerged) and Koizumi, Sasai, Ikeda, and Motoe (2012) and Koizumi, Ikeda, and Motoe (2013, 2014), which revealed the current status of fabrication facilities typified by Fablab. However, since the former is a single case and the latter is a series of case studies focused on fabrication facilities, they all have the same limitations as the aforementioned studies.
} 
Facility ${ }^{6}$

The average number of desks has been trending upwards from 38, to 40 , and then to 41 from the first survey to the third. While the number of desks is less than 19 at nearly one third of the spaces, it is over 50 at one fourth of them. Looking at it by region, while the average number of desks at spaces in Europe is 34, it is 43 -almost $30 \%$ more-at spaces in the United States. Whereas two thirds of the spaces in the United States have a capacity of over 30 people, comparable spaces account for less than one third of spaces in Europe.

In terms of facility usage, while one half of spaces in the United States use flexible desks, only one third of spaces in Europe do. Notably, only $7 \%$ of all spaces provide private rooms as main offerings. ${ }^{7}$

On average, it takes seven months to open a facility.

\section{Management Organization ${ }^{8}$}

The average number of staff members at the time of opening a space was 2.8. Looking at it by facility size, while one third of small spaces with less than 10 members were opened by one individual, 2.2 individuals were involved on average. For spaces that offer more than 50 seats, four individuals are involved in opening. The survey also indicated that the number of space managers tends not to increase as the number of members increase.

In terms of the entity that operates a space, $80 \%$ are private, $13 \%$ are NPO (Non-profit Organization)s, and the remaining are government-related organizations. In addition, $74 \%$ of space managers have a second job.

The average cost of opening a space is 46,500 euros in Europe and 58,000 dollars in the United States; the levels of investment are thus quite similar, considering the foreign exchange rate. As for the procurement of opening funds, two thirds used their own funds. Those who used bank loans and funding from venture capital were in the minority, accounting for $13 \%$ and $5 \%$, respectively. Only a few spaces opened by using crowdfunding or government aid. Incidentally, cases of self-funding are relatively rare among large spaces; in many cases, they use bank loans and private investments.

As for length of time the space has been in operation, although the average is 18 , more than $50 \%$ of the spaces have been in operation for less than 12 months. The results by region are not very different: 16 months in Europe and 18 in the United States.

\section{Business Strategy ${ }^{9}$}

Coworking space's strongest competitor is the home office. Specifically, while most (58\%) users have switched their workplace from the home to a coworking space, those who transitioned from corporate offices accounted for only $22 \%$, and the rest accounted for even smaller percentages. The survey also shows that about 5.3 coworking spaces were operating within the same city.

\footnotetext{
${ }^{6}$ Here, refer to the first GCS unless otherwise noted.

7 The second GCS.

8 Ibid.

${ }^{9}$ Ibid.
} 
Furthermore, the vast majority (83\%) of the spaces interact with other spaces in the region or local community; only a few (10\%) spaces do not communicate at all with anyone else.

\section{Activity}

The average number of events held at a space per month is 4.5 . However, while $21 \%$ of all spaces hold two events on average, 15\% hold 10 events or more. By region, spaces in the United States hold events more frequently — seven times per month on average- than spaces in Europe, where an average of five events are held per month. Regarding size, the GCS also reports that the event participation rate is higher among spaces with a capacity of 50 people or more. ${ }^{10}$

Regarding the type of events, events for facilitating some kind of networking (e.g. common meals), workshops (e.g. legal advice, intro to coding), and presentation/ information sessions each accounts for a large percentage: $75 \%, 72 \%$, and $65 \%$, respectively. ${ }^{11}$

\section{Space Users ${ }^{12}$}

First, we will direct attention on the findings related to the attributes of users. The average age of users is $34 .{ }^{13}$ Most (78\%) users are under the age of 40 , and those under 30 account for $41 \%$. By region, the average age is 34 in Europe and Canada and 33 in the United States, showing almost the same results. Regarding the size of the city where spaces are located, the average age is 32 in cities with a population of one million and 43 in cities with a population of less than 20,000 people, showing a gap of about 10 years.

In terms of the employment status of users, $54 \%$ are freelancers, $20 \%$ are entrepreneurs who employ others, and 20\% work as a permanent employee (most working at a company with fewer than five employees ${ }^{14}$ ). By age group, while some coworking space users in the older segment (aged 50 to 64) are freelancers and some coworkers in the younger segment (aged 20 to 34) are employees of large companies, there are also many small business entrepreneurs. By region, about two thirds of the users are freelancers or small business owners in both Europe and the United States, which is below the average. Usage by company employees is relatively high ( $35 \%$ in the United States, for example).

Regarding occupation, web development/design (44\%) and public relations/marketing (13\%) are relatively common. Overall, most users are in technical professions. Looking at it by age group, $42 \%$ of younger coworkers are web or IT developers. This figure drops to $25 \%$ among middle-aged users and down to $12 \%$ among older users. Meanwhile, we can find more consultants, PR experts, designers, and journalists in the older segment. By region, while in Europe there are slightly less programmers in coworking spaces than in North America, and a few more people working as architects and consultants in Europe.

\footnotetext{
10 Ibid.

11 The third GCS.

12 Refer to the first GCS unless otherwise noted.

13 The result in the second survey remained the same, at 34 years old. That said, it has been noted that the user base is expanding to both older and younger segments.

14 Those who work for companies with more than 100 employees account for $8 \%$ of the users in the United States.
} 
The average number of members trends up from 38 to 44 between the second and third surveys. By region, the average number of members is 30 and 44 per space in Europe and the United States, respectively. ${ }^{15}$ Two-thirds are male.

Next, we will focus on the findings about the behavior and attitude of users. Concerning the meaning and value of coworking space, almost all (96\%) users said that the community was valuable for space members. In addition, interactions with other people (84\%), flexibility of the hours of use (83\%), and the encouragement of serendipitous discoveries (82\%) were mentioned as being important elements for coworkers. ${ }^{16}$

In fact, $81 \%$ of the users in the first survey expressed a desire for a strong community; ${ }^{17}$ three quarters expressed a longing to share knowledge with others and look for the community in the space in the second survey. This is associated with the fact that $51 \%$ want a relatively small space with less than 20 people. In addition, many respondents prefer to use spaces with flexible hours of work (use): only 30\% want traditional hours of work (use). In Europe, 96\% consider the flexible working hours to be important. Regarding the use of facilities, $47 \%$ want permanent desks while $51 \%$ want flexible desks.

How are they using the spaces? Most choose a monthly plan, and only $10 \%$ choose a daily or weekly plan. ${ }^{18}$ Most users choose a plan that allows them to use the space 24 hours a day, 365 days a year; this is the same in both Europe and the United States (60\%). In terms of the number of days of space use, many users visit the space very frequently: one third use the space every day, and $60 \%$ use the space more than three or four times a week. ${ }^{19}$ Regarding form of usage, flexible seating, which accounts for two thirds, exceeded permanent seating (one quarter). In addition, two thirds have used only their current space; only a few (4\%) have used multiple spaces. ${ }^{20}$

We will now direct attention on users' activities at their spaces. In terms of the unit in which to conduct an activity, $57 \%$ of all users said they often engage in work by forming a team. ${ }^{21}$ In terms of age groups, users prefer team activities to individual activities; the younger users tends to want to be involved in each project over a long period of time. In terms of space size, $74 \%$ of those who use small spaces and 53\% of those who use large spaces said they often have an opportunity to work in a team.

What benefits do users gain by using a space? Of all users, $88 \%$ said they have been able to have good interactions ${ }^{22}$ with others. ${ }^{23}$ Specifically, users at a space with fewer than 10 desks are building beneficial relationships with 10 people. The figure drops to five at a space with 10 to 19

\footnotetext{
15 The second GCS.

${ }^{16}$ Ibid.

17 The figure remains 55\% among space users in Europe.

18 The second GCS.

19 The majority (47\%) uses the space regardless of time and day of week (24 hours a day, seven days a week).

20 The second GCS.

${ }^{21}$ However, according to the second survey, the majority (53\%) is satisfied with working individually.

22 In the third survey, users said they engage in chitchat with other users (77\%), talk about each other's employer (72\%), and share knowledge and advice (62\%).

${ }^{23}$ In the second survey, the majority (74\%) of users knows the names of all or many of their fellow users. The majority (77\%) of users also socialized with at least some of the other users after work or at the weekends. While close to $30 \%$ (27\%) socialize with almost all the users at least sometimes, only some (15\%) users never interact with other users outside of work.
} 
desks and then increases up to seven people at a space with 60 or more desks. This suggests that there are many opportunities to make a new connection with others when the space is either small or large. However, as the space size increases, the tendency to work as a team or enjoy good interactions with others decreases. Younger coworkers have made an average of six valuable new connections within two months of joining a space. ${ }^{24}$ Although the figure slightly declines among middle-aged users, it increases to seven among older users. The second survey showed that there were effects such as "The social circle was expanded through the use of the space” (92\%), "The sense of isolation was reduced" (86\%), "The business network was expanded" (80\%), and "The productivity of work was increased" (75\%). The third survey reported that the users saw changes in ideas related to business (74\%), creativity (71\%), able to focus (68\%), completing the tasks in given time (64\%), and standard of work (62\%).

Finally, we will direct attention on how users rate the space. Almost all (more than 90\%) users in both Europe and the United States are satisfied with the space, and most of them (two thirds) do not intend to leave the space. In the second survey, the average score for satisfaction with the space was 8.4 on a 10-point scale. Furthermore, the results showed that the users like aspects of the space such as people (81\%), location (61\%), and price (46\%), and most (68\%) do not intend to switch spaces. In the third survey, the average level of satisfaction stayed almost the same (8.3), a high score. By region, the scores are 8.2, 8.4, 8.7, 8.5, and 8.5 in Europe, North America, Latin America, Asia, and Africa, respectively, exhibiting no large differences.

\section{Performance ${ }^{25}$}

The average desk utilization rate trended upwards from $44 \%$ to $50 \%$ and $55 \%$ from the first survey to the third. In the first survey, the rate is $54 \%$ in Europe and $43 \%$ in the United States and Canada. There is no large difference in terms of the size of the city where the space is located, since the rate is $48 \%$ among spaces in large cities and $44 \%$ among spaces in small cities. The survey also shows that the utilization rate is inversely proportional to the number of seats.

The average desk occupancy rate trends downwards from $109 \%$ to $101 \%$ from the second survey to the third. For spaces with 100 or more desks, the average rate is $172 \%$, far exceeding the overall average. The number of members who share each desk tends to increase as the space grows larger.

In terms of space business revenue, nearly half (40\%) are making a profit. While most (56\%) spaces with fewer than 10 seats are incurring a loss and profitable spaces are the minority (25\%), the majority (70\%) of spaces with 50 seats or more are making a profit, and only some (20\%) of the spaces are operating at a loss. On average, the number of members has increased by approximately $30 \%$ since the time of opening, and profits tend to increase as members increase. Concerning region, whereas the incomes and expenses at half of the spaces in the United States are at either

\footnotetext{
${ }^{24}$ In a related item, the second survey shows that on average, most users had met 3.6 useful new acquaintances in the past two months.

${ }^{25}$ Here, the results are limited to those related to the space business. Unless otherwise noted, the descriptions refer to the second CGS.
} 
breakeven or profitable, the figure is only $30 \%$ in Europe; quite a few spaces cannot make a profit.

Most (72\%) spaces exceed the breakeven point and become profitable after two years in operation. This figure increases to $87 \%$ when only private space is considered. Interestingly, a space tends to become more profitable and reach the breakeven point faster when the number of spaces operated in a given area is higher. By contrast, a monopolistic space in a given city is two times more likely to become unprofitable than an average space, indicating that demand is higher and the concept better known in areas with more spaces.

Concerning a space manager's income, many (64\%) full-time space managers of spaces with less than 30 members are earning as much or more than the average income.

\subsection{Research Question}

We have reviewed previous studies on coworking and coworking space. The results confirmed that studies attempting to describe and explain the phenomenon have gradually been accumulated in Japan and overseas. However, with the exception of the GCS annual worldwide survey, most studies are small and limited in scope and target population, thus failing to assist an understanding of the overall picture of the operation and utilization of coworking space. In addition, although the analysis results of the GCS are certainly useful, it comprises a consolidation of data drawn from around the world. Though it mentions regional differences in the analysis results, elements such as regional characteristics, industry and employment structure, and the attitudes and behavior of working people may differ by country. Therefore, it is necessary to accumulate suggestive findings on the operation and utilization of spaces in each country concurrently with significant efforts like the GCS.

Therefore, this paper focuses on coworking spaces in $\operatorname{Japan}^{26}$ and empirically examines their status.

\section{Research Method}

The dataset used in this paper is based on data obtained from a questionnaire survey we conducted independently. The survey was conducted online over the 38 days from July 28 to September 3, 2014 by using an online research company.

The sample population for the questionnaire survey was extracted through the following procedure. First, we used the dataset uploaded on Coworking JP's Facebook page. ${ }^{27}$ We used the file dated January 28, 2014, which was the latest file as of the June 2014 period when we began preparing for the survey. In addition, as the number of coworking spaces was trending up, we also used other websites and updated the dataset. ${ }^{28}$ Responses were obtained from 191 spaces out of the 365 that represented almost all facilities in operation in Japan as of July 2014 (a 52.3\% response

\footnotetext{
26 We focus on coworking spaces in this paper because they do not change over time as much as coworkers, allowing us to obtain basic knowledge and helping us understand the overall picture of the phenomenon of coworking.

27 Coworking JP (https://www.facebook.com/groups/cowjp/).

${ }^{28}$ We used websites such as coworking-space JP (http://coworking-space.jp/) and coworking.com (http://co-work-ing.com/).
} 
rate). We asked space managers to fill out the questionnaire. We also decided to limit the target population to the spaces that allow drop-in (i.e., temporary) usage because we believed that, as shown in Uda (2013), the nature of coworking is best exemplified in spaces where an openness of workspace and a diversity of members are expected. As a result, 152 responses were used in the analysis. ${ }^{29}$

\section{Descriptive Statistics}

In what follows, we present the descriptive statistics from six perspectives-facility, management organization, business strategy, activity, space users, and performance-as we did when we reviewed the findings of the GCS in 2.2.

\subsection{Facility}

As shown in Table 1, the floor sizes of the coworking spaces we received responses from ranged from a low of eight square meters to a high of 1,000 square meters. Since the difference between the lowest and highest is so large, there appears to be meaningless in showing the average. Therefore, we present Figure 1, showing that 100 spaces (65.8\%) are under 100 square meters. There are 22 (14.5\%) large spaces with 200 square meters or more.

Table 1: Floor Size, Number of Seats, and Number of Partitioned Seats

\begin{tabular}{lrrrrr}
\hline & \multicolumn{1}{c}{ Mean } & Median & \multicolumn{1}{c}{ SD } & Min. & \multicolumn{1}{c}{ Max. } \\
\hline Floor size $\left(\mathrm{m}^{2}\right)$ & 123.95 & 80.50 & 148.20 & 8 & 1000 \\
Number of seats & 33.89 & 26.00 & 26.76 & 4 & 150 \\
(Number of seats / Floor Size) & 0.41 & 0.33 & 0.28 & 0.02 & 1.60 \\
Number of partitioned seats & 5.75 & 0.00 & 10.13 & 0 & 60 \\
\hline
\end{tabular}

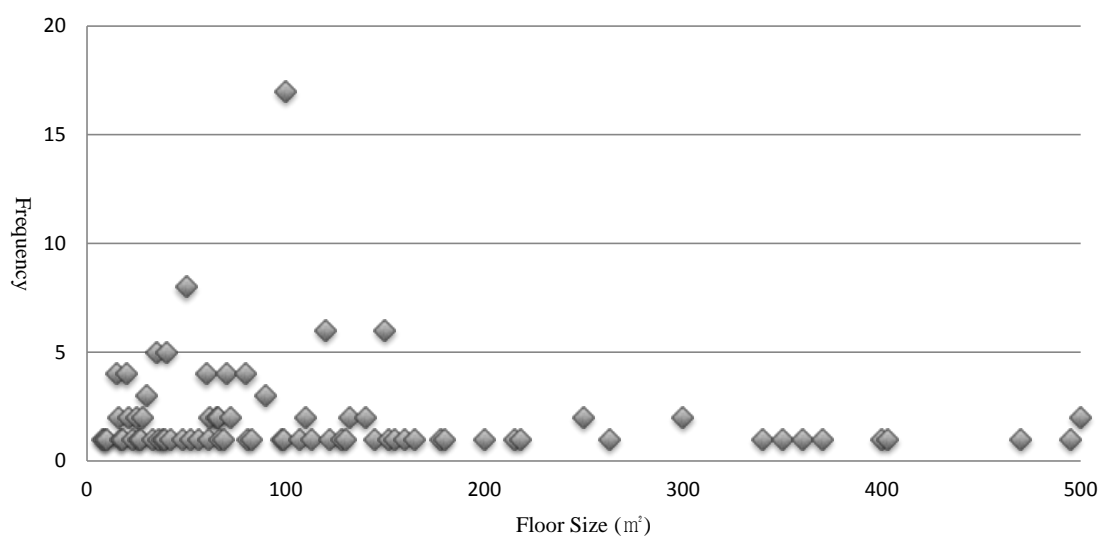

Figure 1: Distribution of Floor Size

29 See pages 133 to 135 in Abe and Uda (2015) regarding the question items. 
Next, we will check the number of seats. The average is 33.9. As with floor size, Table 1 shows that there is a large difference between the lowest (four seats) and the highest (150 seats). As shown in Figure 2, there are 21 spaces (13.8\%) with 10 or fewer seats and 60 spaces (39.5\%) with 20 or fewer seats. The average number of seats per square meter is 0.4. In other words, they have about one seat per 2.5 square meters.

The average number of partitioned seats is 5.8. There are 82 spaces (53.9\%) that do not offer partitioned seats. These spaces seem to have an open floor overlooking the entire area. Checking on the 70 spaces that have partitioned seats, the fewest number of partitioned seats was one while the highest was 60 .

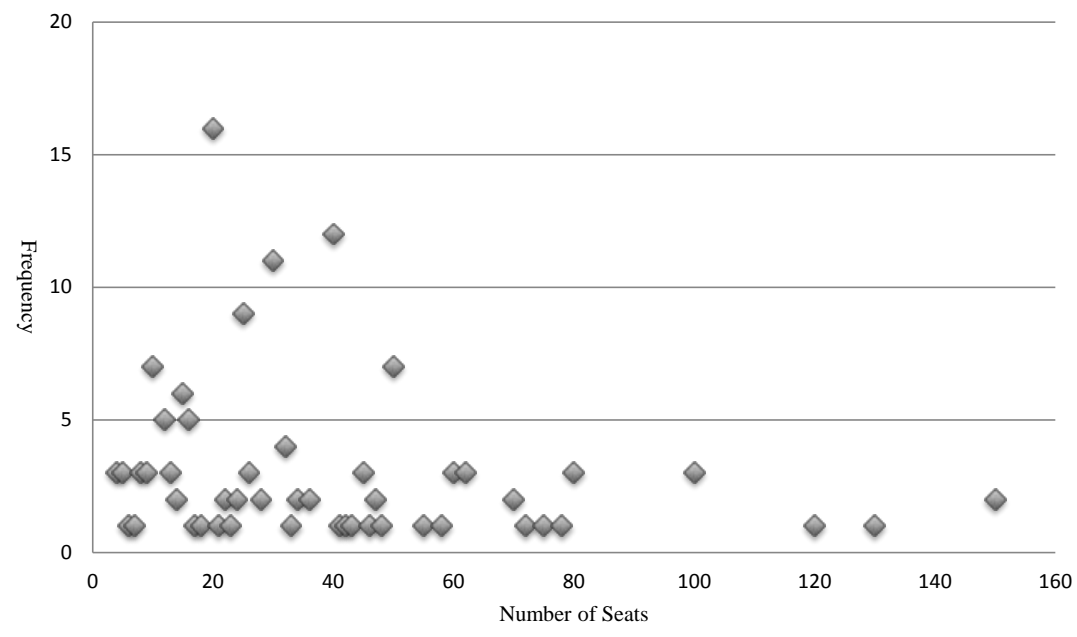

Figure 2: Distribution of the Number of Seats

\subsection{Management Organization}

\subsubsection{Positioning of Space Business}

Of all respondents, 14 (9.4\%) specialize in the space business. ${ }^{30}$ There are 37 spaces (24.8\%) where operating a space is the main business and 98 spaces that say their main business is something other than operating a space. ${ }^{31}$ Therefore, $65.8 \%$ of all spaces are operating a space as a side business.

\subsubsection{Area of Business}

We also check on the area and extension of business among the 135 spaces that operate some kind of business other than spaces. ${ }^{32}$ Here, the question includes a total of 10 categories: (1) IT-related, (2) creative/design-related, (3) Manufacturing-related, (4) real estate-related, (5) childcare/women's support-related, (6) building/construction-related, (7) food and beverage-related,

\footnotetext{
30 It should be noted that these 14 spaces include some that founded a separate entity such as corporation in order to operate a coworking space, in addition to individuals and corporations that operate coworking spaces only.

31 The sample size is 149 because three out of the 152 spaces included here had a missing value.

32 We excluded 14 spaces that operate coworking spaces only and looked at 135 spaces.
} 
(8) government-related, (9) educational institutions, and (10) other.

First, we will check on the specifics of each space's business area. Respondents were asked to choose all that apply from a total of 10 categories. As shown in Figure 3, IT-related (54), creative/design-related (42), and other (47) account for many responses. ${ }^{33}$ Meanwhile, there are only a few building/construction-related (10) and government-related (5).

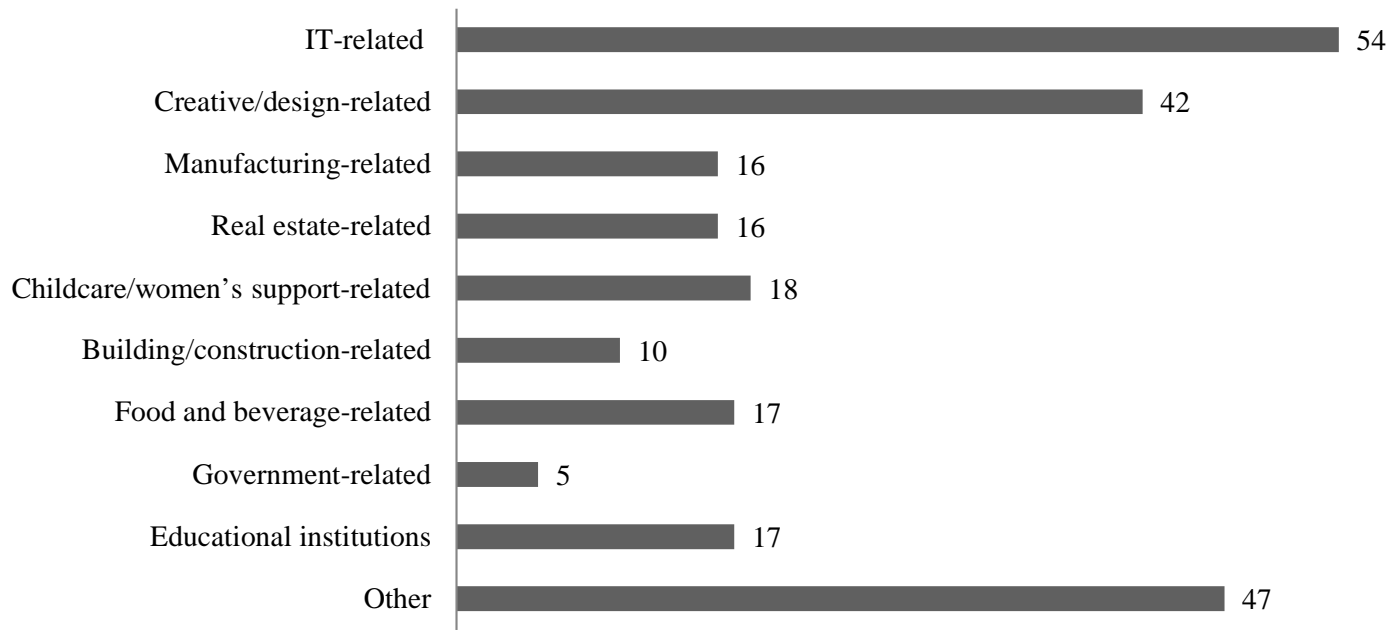

Figure 3: Each Space’s Area of Business (multiple answers are allowed)

Next, we check on the number of business areas by simply adding up these 10 categories. As shown in Figure 4, there are 109 spaces (73.2\%) that are engaged in one or two businesses other than space.

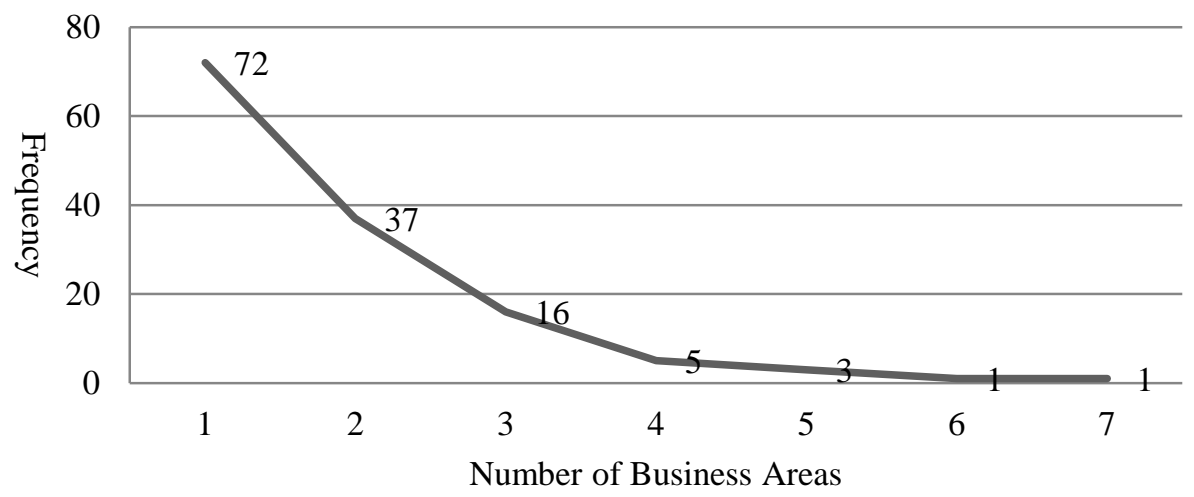

Figure 4: Distribution of the Number of Business Areas Other than Space Operation

\footnotetext{
33 Respondents were asked to specify the business when they chose "other.” We plan to examine what they are in
} another paper. 


\subsubsection{Management Structure}

We asked about the number of staff involved in the operation and the space manager's working hours (i.e., daily basis, weekly basis, and the change since opening the space).

Table 2 shows the number of staff. The average is 5.57. As, you might infer from the fact that the median is 4, 94 spaces (61.8\%) are actually operated by fewer than five people. Looking at the breakdown of the staff, the most common employment status is full-time including a space manager (2.63 staff members on average) ${ }^{34}$ followed by part-time, volunteer, and intern.

Table 2: Number of Staff

\begin{tabular}{lrrrrr}
\hline & $\begin{array}{c}\text { Full-time } \\
\text { including } \\
\text { space manager }\end{array}$ & Part-time & $\begin{array}{c}\text { User } \\
\text { Volunteers }\end{array}$ & Interns & Total \\
\hline Mean & 2.63 & 1.40 & 1.19 & 0.36 & 5.57 \\
Median & 2 & 0 & 0 & 0 & 4 \\
SD & 4.445 & 2.453 & 2.691 & 1.407 & 5.792 \\
Min. & 0 & 0 & 0 & 0 & 0 \\
Max. & 50 & 16 & 20 & 13 & 50 \\
\hline
\end{tabular}

Next, we examine space manager's working hours. As shown in Table 3, on average, a space manager works 7.29 hours per day and is involved in the activities of the space 4.74 days per week. Space manager's total number of weekly working hours, estimated by multiplying these two numbers, is 34.6. Table 4 shows the change in working hours since the opening of the space. Space managers at 88 spaces (57.9\%) answered that their working hours have not changed since the space was established.

Table 3: Working Hours per Day and Working Days per Week of Space Manager

\begin{tabular}{lrr}
\hline & $\begin{array}{c}\text { Working hours } \\
\text { per day }\end{array}$ & $\begin{array}{c}\text { Working days } \\
\text { per week }\end{array}$ \\
\hline Mean & 7.29 & 4.74 \\
Median & 8 & 5 \\
SD & 3.680 & 1.759 \\
Min. & 0 & 0 \\
Max. & 18 & 7 \\
\hline
\end{tabular}

\footnotetext{
34 There are seven spaces where the number of full-time workers is zero. Many are operated by user volunteers and part-time workers.
} 
Table 4: Change in Working Hours Compared to Immediately After Opening

\begin{tabular}{lrr}
\hline & Freuquency & \multicolumn{2}{c}{ Percentage (\%) } \\
\hline Become longer & 22 & 14.5 \\
No change & 88 & 57.9 \\
Become Shorter & 42 & 27.6 \\
\hline Total & 152 & 100 \\
\hline
\end{tabular}

\subsubsection{Space Manager}

We obtained responses regarding space manager's areas of expertise, gender, age, and management experience. For area of expertise, the following categories were presented: (1) IT-related, (2) creator/designer-related, (3) Manufacturing-related, (4) community development-related, (5) childcare/women's support-related, (6) building/construction-related, (7) literary/writer-related, (8) sales/marketing-related, (9) clerical-related, and (10) other. Multiple answers are allowed for area of expertise. As shown in Figure 5, while 43 respondents chose "IT-related," 45 respondents chose "other." 35

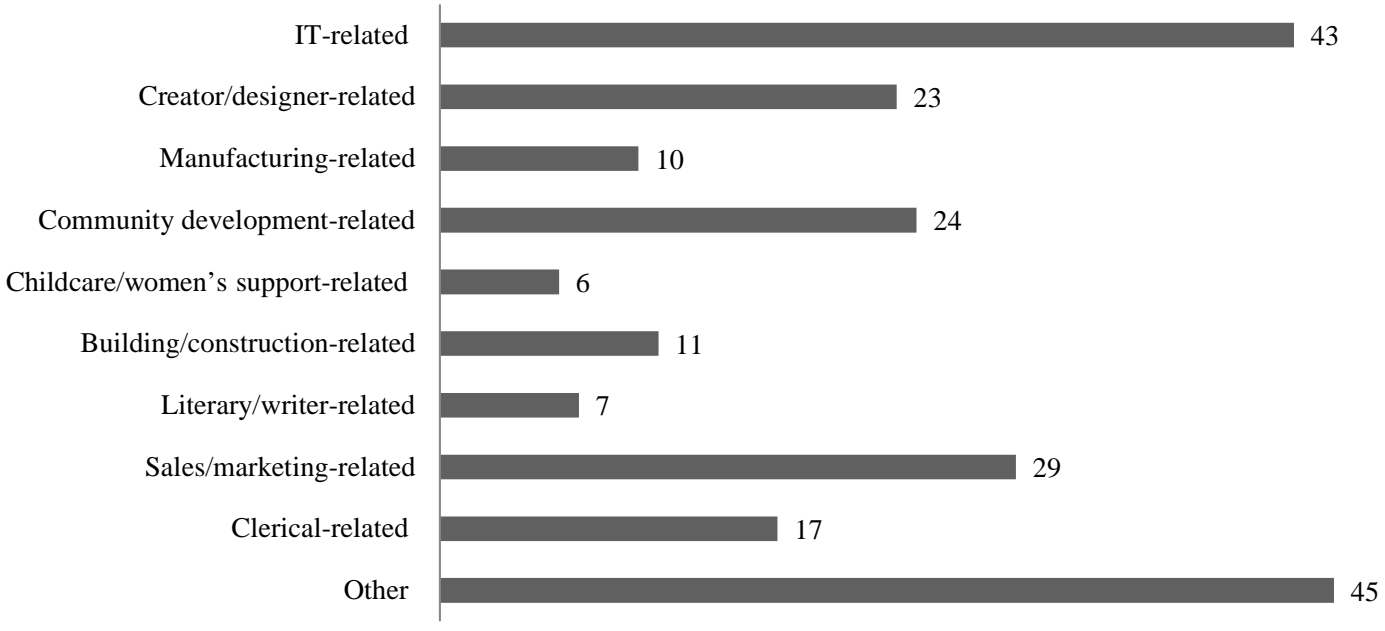

Figure 5: Space Manager’s Area of Expertise

The male/female breakdown of space managers is $74.3 \% / 25.7 \%$. As shown in Table 5 , the average age of space managers was 38.91. Figure 6 shows the distribution of the ages. The youngest was 18 and the oldest 65 . As you might infer from the median of 37 and the standard deviation of 8.945, space managers in their 30s and 40s actually account for 109 (72.2\%) overall.

\footnotetext{
35 Respondents were asked to specify areas of expertise when they chose "other" for this question as well. We plan to examine what they are in another paper.
} 
Table 5: Age of Space Manager ${ }^{36}$

\begin{tabular}{lr}
\hline Mean & 38.91 \\
Median & 37 \\
SD & 8.945 \\
Min. & 18 \\
Max. & 65 \\
\hline
\end{tabular}

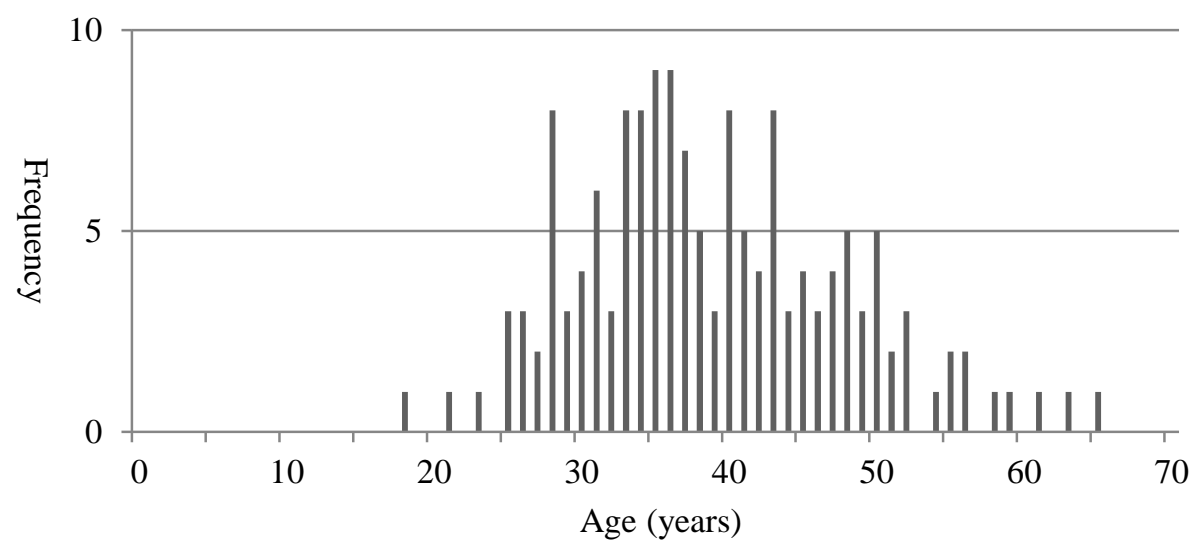

Figure 6: Distribution of Space Manager’s Age

As Table 6 shows, the space manager's average management experience was 19.49 months, or a little more than a year and a half. The shortest management experience was one month and the longest was 80 months, or a little under seven years. ${ }^{37}$ In addition, as you can see from Figure 7, space managers with less than three years (36 months) of management experience account for 94.1\% (143).

Table 6: Space Manager’s Experience in Managing a Space (in months)

\begin{tabular}{lr}
\hline Mean & 19.49 \\
Median & 19 \\
SD & 12.236 \\
Min. & 1 \\
Max. & 80 \\
\hline
\end{tabular}

36 The sample size is 151 .

37 Japan's first facility to be billed as a coworking space is said to be Cahootz, which opened in Kobe in May 2010. 


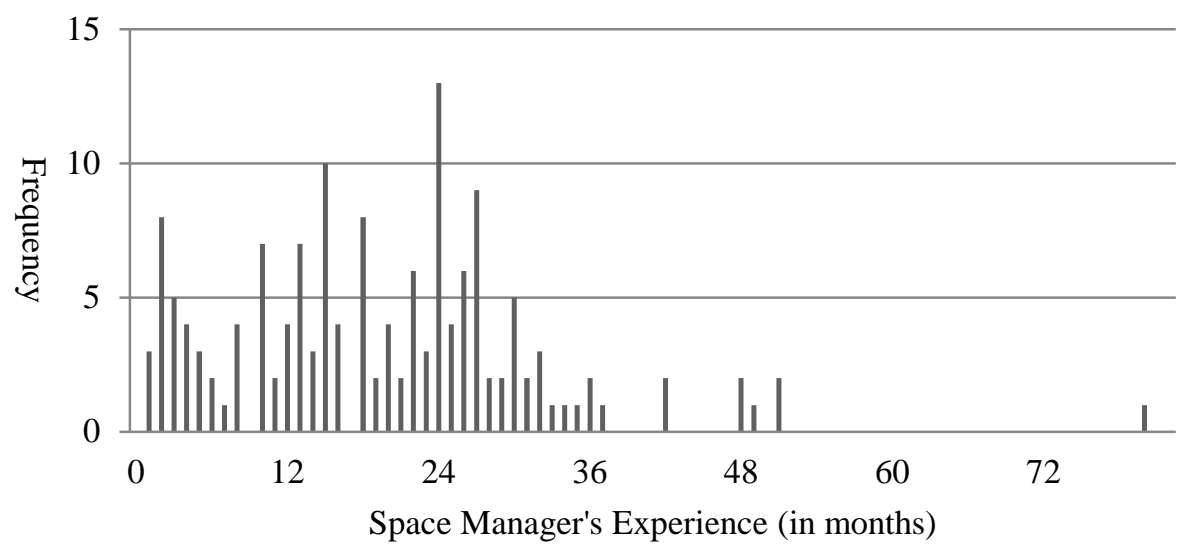

Figure 7: Distribution of Space Manager’s Experience in Managing a Space (in months)

\subsection{Business Strategy}

\subsubsection{Management Policy}

We asked 10 questions regarding the management policy of the spaces. Specifically, we asked that the following 10 items be rated on a five-point scale ( 1 = "disagree completely;" 5 = "agree completely"): (1) "Coworking spaces in the neighborhood are business competitors" ( "compete with neighboring spaces"; (2) "Focus on the profitability of the coworking space itself" ("focus on profitability"); and (3) "Focus on community formation at the coworking space" ("focus on community formation”); (4) "Cooperate with coworking spaces in the neighborhood” ("cooperate with neighboring spaces"); (5) "Cooperate with coworking spaces outside the neighborhood" ("cooperate with distant spaces"); (6) "Actively involved in the local community where the coworking space is located" ("cooperate with the local community); (7) "Cooperate with other companies" (“cooperate with other companies”); (8) "Cooperate with the local government" (“cooperate with the government”); (9) "Cooperate with NPOs” (“cooperate with NPOs”); (10) "Cooperate with public institutions such as vocational schools, universities, and hospitals" ("cooperate with public institutions");:These items can be roughly divided into those on the space management policy (questions 1 through 3 ) and on the state of cooperation (questions 4 through $10)$.

Table 7 shows the averages for all 10 items. Figure 8 shows the distribution of the responses to these 10 items. First, we examine three items on the spaces' management policy. Looking at the item "compete with neighboring spaces," the average is low (mean of $1.86 \fallingdotseq$ "somewhat disagree”), with the distribution declining to the right. This suggests that many space managers do not perceive neighboring spaces as competitors ${ }^{38}$. For "focus on community formation," 127 spaces (83.6\%) said "somewhat agree" or "completely agree.” The frequency distribution shows an increase to the

38 Then, how space managers consider neighboring spaces? We see in Figure 8 that 50 spaces (32.9\%) tend to cooperate with neighboring spaces, and 76 (50.0\%) tend not to cooperate with neighboring spaces; these could be roughly divided into two groups in terms of cooperation with neighboring spaces. 
right. Thus, most space managers are focusing on community formation. ${ }^{39}$ By contrast, the mean score is 2.68 for "focus on profitability." The number of spaces that tend not to focus on profitability is 83 (54.6\%), exceeding the 48 spaces (31.6\%) that tend to focus on profitability. This suggests that, in general, they do not really focus on profitability. Many spaces are for-profit businesses operated by entities such as private companies. Nevertheless, such a trend is observed, perhaps because the majority (65.8\%) of spaces consider operating a space as a side business, as shown in 4.2.1.

The responses to these two items suggest that, while space managers focus on community formation, they do not really focus on profitability.

Next, we examine the characteristics of items related to the cooperation. Looking at the average, we see that space managers are focusing on cooperation with the local community (mean $=3.47$ ). Based on the frequency distribution chart, we see that the distribution increases roughly to the right and that 83 spaces (54.6\%) are cooperating with the community in one way or another.

Regarding cooperation with other companies, while 54 spaces (35.5\%) tend not to cooperate, 70 spaces (46.0\%) do tend to cooperate, suggesting that these could also be divided into two groups. For the other items, we cannot say if there is a trend towards cooperation, since the mean scores are below 3 (“neither agree nor disagree”), and many 1 responses (“completely disagree”) are given for not cooperating at all.

Table 7: Management Policy

\begin{tabular}{lrc}
\hline & Mean & SD \\
\hline (1) Comtete with Neighboring Spaces & 1.86 & 0.970 \\
(2) Focus on Profitability & 2.68 & 1.440 \\
(3) Focus on Community Formation & 4.26 & 0.952 \\
(4) Cooperate with Neighboring Spaces & 2.53 & 1.371 \\
(5) Cooperate with Distant Spaces & 2.75 & 1.479 \\
(6) Cooperate with the Local Community & 3.47 & 1.297 \\
(7) Cooperate with Other Companies & 3.07 & 1.486 \\
(8) Cooperate with the Local Government & 2.63 & 1.500 \\
(9) Cooperate with NPOs & 2.44 & 1.427 \\
(10) Cooperate with Public Institutions & 2.24 & 1.285 \\
\hline
\end{tabular}

39 We should also note that this item has the highest mean score (4.26) of all 10 items. 
(1) Compete with Neighboring Spaces

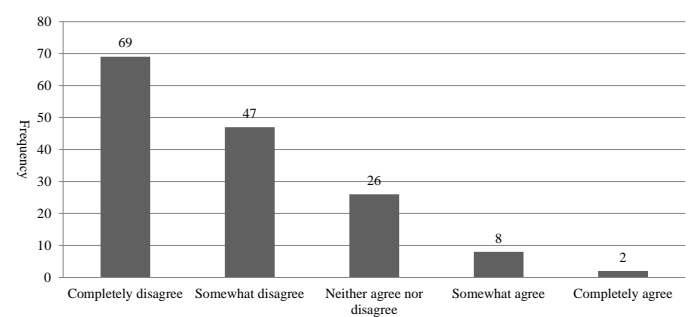

(2) Focus on profitability

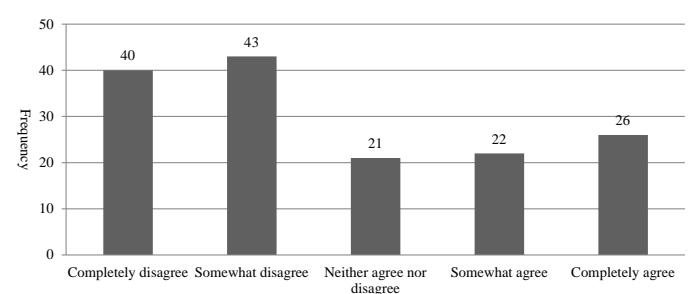

(3) Focus on Community Formation

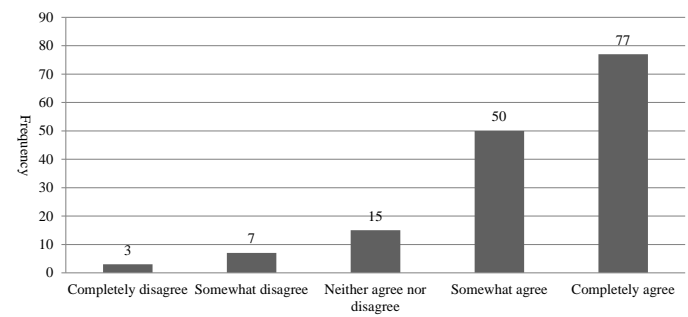

(4) Cooperate with Neighboring Spaces

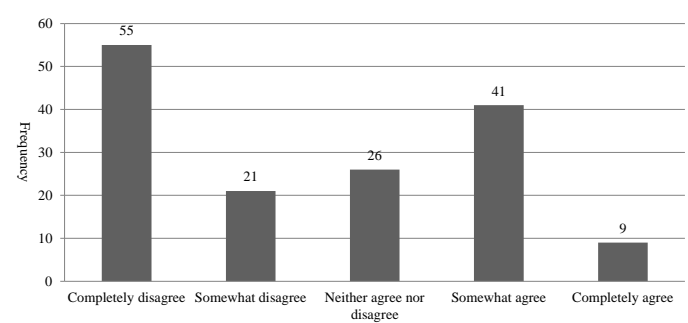

(5) Cooperate with Distant Spaces

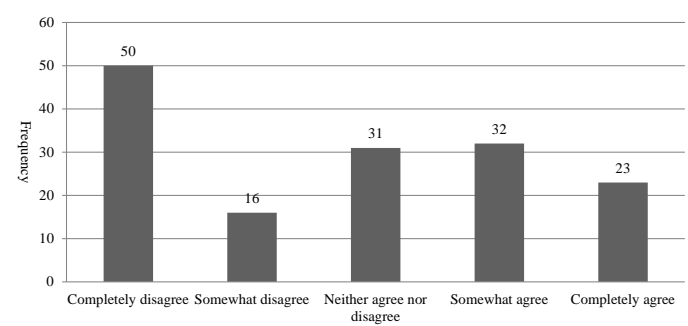

(6) Cooperate with the Local Community

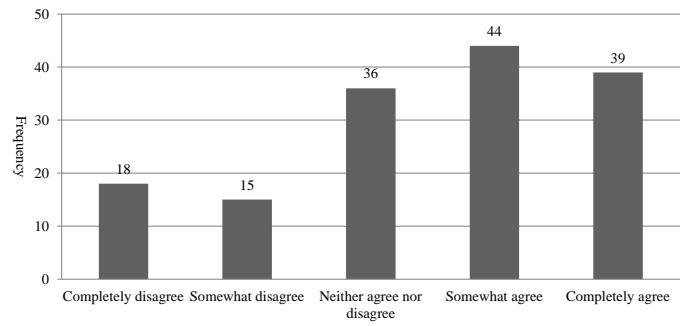

(7) Cooperate with Other Companies

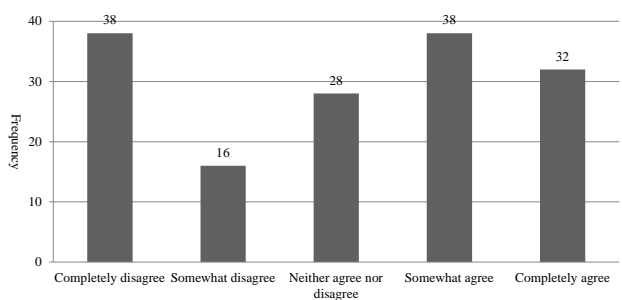

(8) Cooperate with the local Government

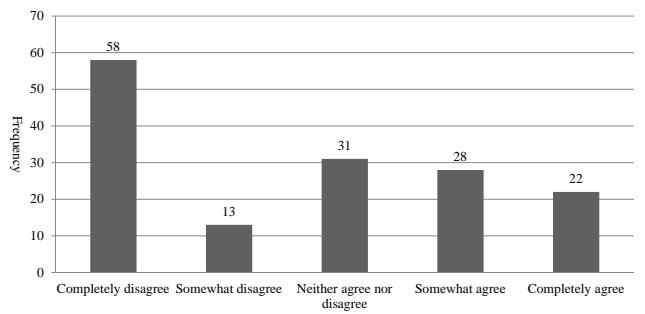

(9) Cooperate with NPOs

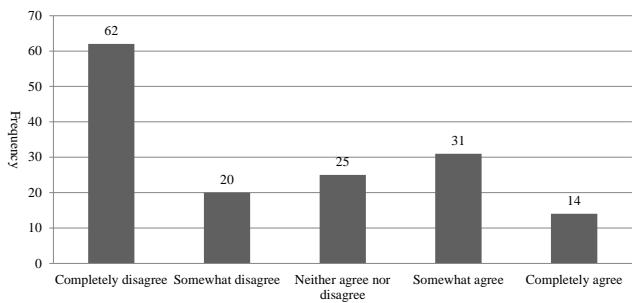

(10) Cooperate with Public Institutions

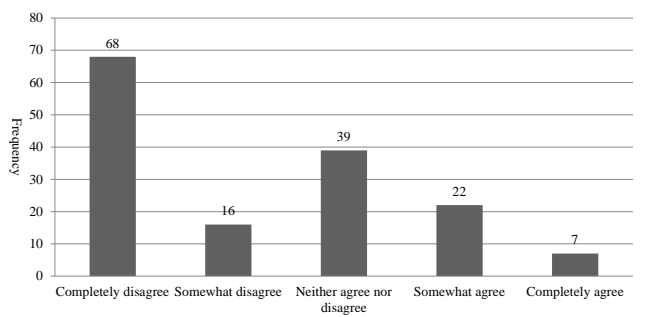

Figure 8: Distribution of Management Policy 


\subsubsection{Competitor for Space}

For this item, we had nine options: (1) cafe/casual restaurant, (2) Internet cafe, (3) rental office/shared office, (4) home/SOHO, (5) corporate office, (6) incubation facility, (7) video conference system, (8) other, and (9) no particular competititors; 28 spaces (18.4\%) said "no particular competititors." 40 Excluding these 28 spaces and focusing on the breakdown of the remaining 124 spaces seems appropriate. As Figure 9 shows, many responses indicate that they consider rental office/shared offices (79), cafe/casual restaurants (67), home/SOHO (55), and incubation facilities (51) to be their competitors. ${ }^{41}$

A space manager perceives a wide variety of competitors. The responses shown in Figure 9 add up to 320; dividing this by the above 124 spaces produces 2.6. Thus, each space manager that indicated some kind of competition mentioned 2.6 competitors. Since they were allowed to choose all options that applied, if many space managers perceived a particular business to be a competitor (e.g., rental office/shared offices), the number of responses for a given choice should increase. However, the responses are not concentrated in a particular choice. Even the rental office/shared office category, which accounts for the highest number of mentions, was mentioned by only 79 (63.7\%) space managers. Therefore, a space manager seems to perceive a wide range of competitors for the space. However, very few respondents chose the corporate office or video conference system, suggesting that they are not considered competitors.

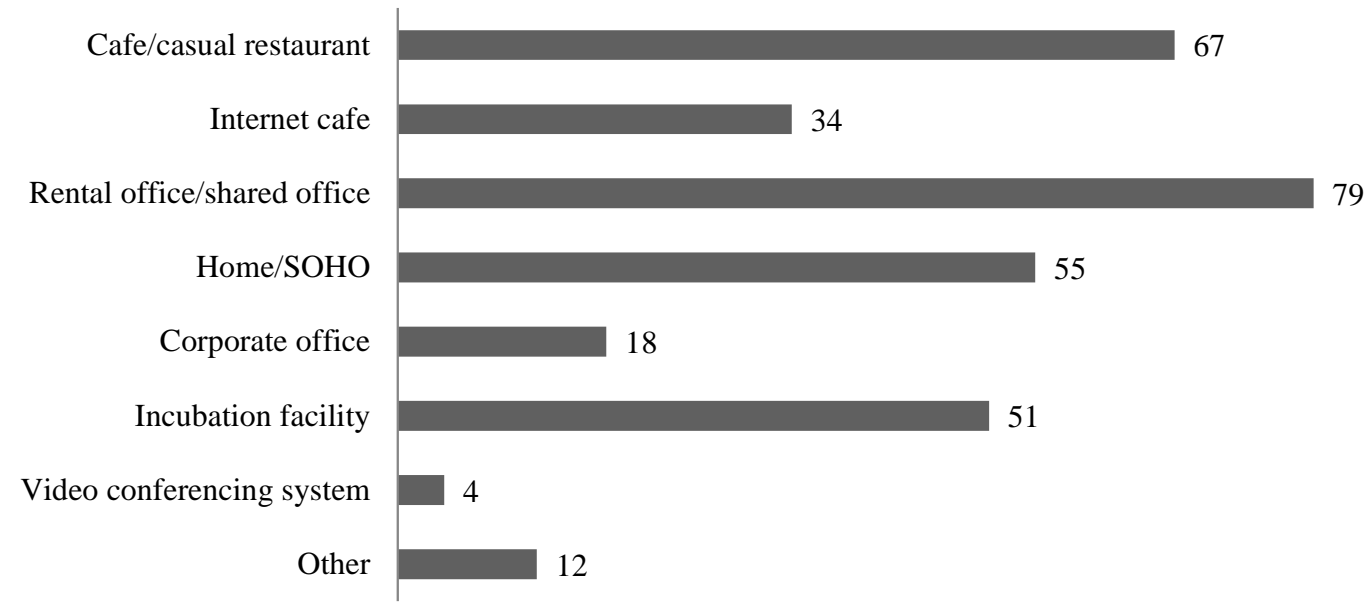

Figure 9: Competitors for the Space

\subsection{Activity}

\subsubsection{Number and Type of Events}

Coworking spaces often hold events. Therefore, we asked about two items: the number and type

\footnotetext{
40 When designing the questionnaire, we programmed the display of an error message and prevented respondents from proceeding to the next question when they chose "no particular competition" along with other options.

${ }^{41}$ Respondents were asked to specify a competitor when they chose "other" in this question as well. We plan to examine what they are in another paper.
} 
of events as well as the event policy. As shown in Table 8, the average number of events and event types held per month is 5.68 and 3.68, respectively. Since the median for the number of events held per month is four, they are probably holding about one event per week. Figure 10 shows the distribution of the frequency of events per month. There are 101 spaces (66.4\%) that hold about one event per week (less than five times). Figure 11 also shows the distribution of the number of event types: 130 spaces (85.5\%) hold about five types of events. These two results suggest that the spaces hold a different type of event at a frequency of about once a week.

Table 8: Number of Events (month) and Number of Event Types (month)

\begin{tabular}{lrr}
\hline & $\begin{array}{c}\text { Number of Events } \\
\text { (month) }\end{array}$ & $\begin{array}{c}\text { Number of Event } \\
\text { Types (month) }\end{array}$ \\
\hline Mean & 5.68 & 3.68 \\
Median & 4 & 3 \\
SD & 6.301 & 3.532 \\
Min. & 0 & 0 \\
Max. & 30 & 20 \\
\hline
\end{tabular}

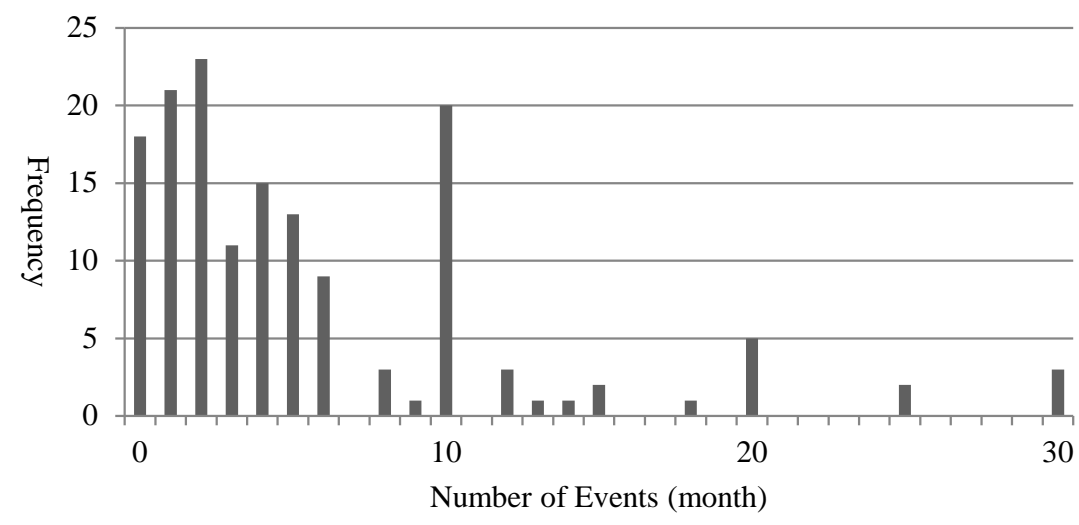

Figure 10: Distribution of the Number of Events (month)

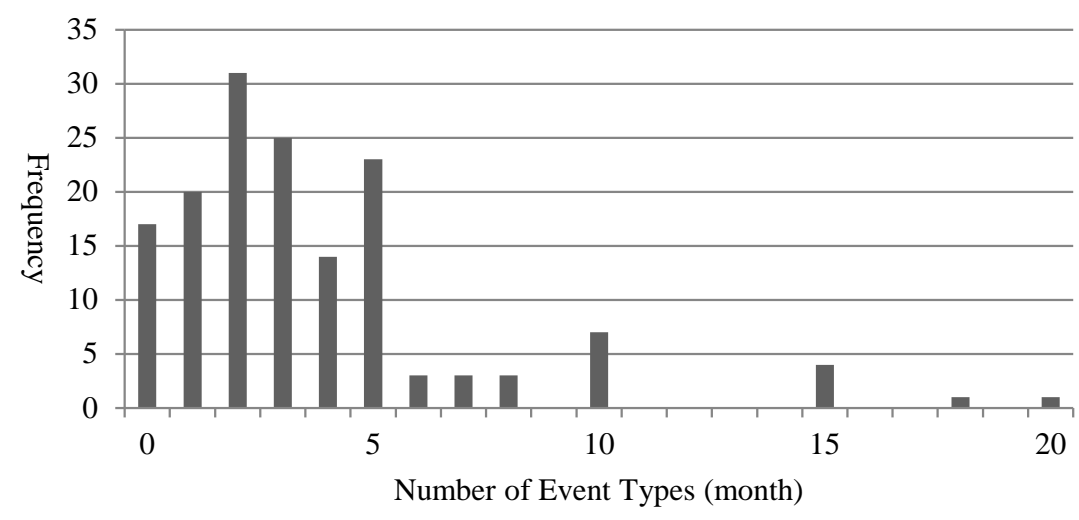

Figure 11: Distribution of the Number of Event Types (month) 


\subsubsection{Space Manager's View on Events}

How does a space manager view events? We asked respondents to rate on a five-point scale a total of 10 items: (1) "Events are an important source of revenue ("events are revenue source" hereafter); (2) "Events help facilitate interactions with people outside the space" ("events help facilitate external interaction"); (3) "Events help facilitate interactions among users within the space” ("events help facilitate user interaction”); (4) "The quality of events is an important issue in operating a space” ("events are space operation issue”); (5) "Events are often planned personally by the space manager" ("events are planned by the space manager"); (6) "Event plans are often proposed by users” (“events are proposed by users”); (7) "The space manager often personally plays roles such as event lecturer" ("the space manager works as event lecturer"); (8) "Users often play roles such as event lecturer" ("users work as event lecturer"); (9) "Events help increase the number of users" ("events help increase users"); and (10) "Events are important for the space" (“events are important”).

The responses to these 10 is are shown in Table 9 and Figure 12. The mean scores are high for "events are important” (mean = 4.26), "events help facilitate external interaction” ( "events are space operation issue" (mean = 3.84), "events help facilitate user interaction" (mean= 3.79), "events are revenue source" (mean = 3.34), and "events help increase users" (mean = 3.33). This suggests that space managers have positive views of events. In addition, while 84 spaces (55.3\%) perceive events as a revenue source, events are not an important revenue source for 44 spaces (28.9\%).

Table 9: Space Manager’s View on Events

\begin{tabular}{lcc}
\hline & Mean & SD \\
\hline (1) Events are revenue source & 3.34 & 1.372 \\
(2) Events help facilitate external interaction & 4.05 & 1.078 \\
(3) Events help facilitate user interaction & 3.79 & 1.194 \\
(4) Events are space operation issue & 3.84 & 1.128 \\
(5) Events are planned by the space manager & 3.29 & 1.125 \\
(6) Events are proposed by users & 3.13 & 1.031 \\
(7) The space manager works as event lecturer & 2.49 & 1.086 \\
(8) Users work as event lecturer & 3.18 & 1.036 \\
(9) Events help increase users & 3.33 & 1.002 \\
(10) Events are important & 4.26 & 0.938 \\
\hline
\end{tabular}


(1) Events Are Revenue Source

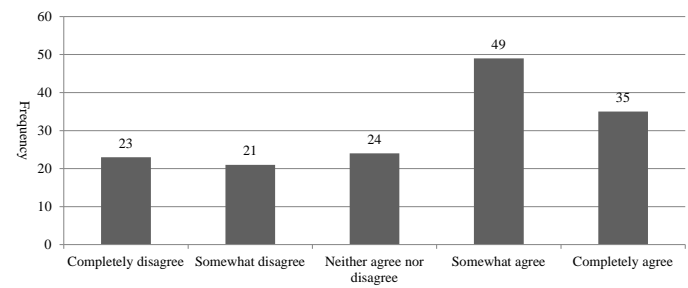

(2) Events Help Facilitate External Interaction

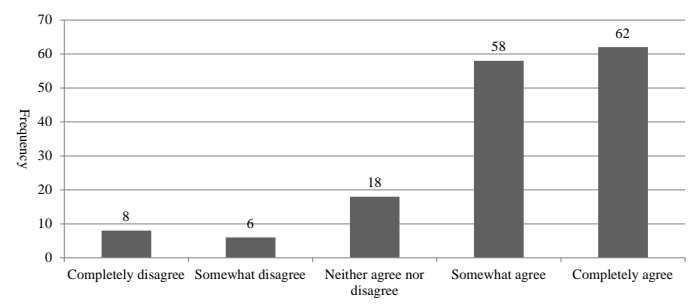

(3) Events Help Facilitate User interaction

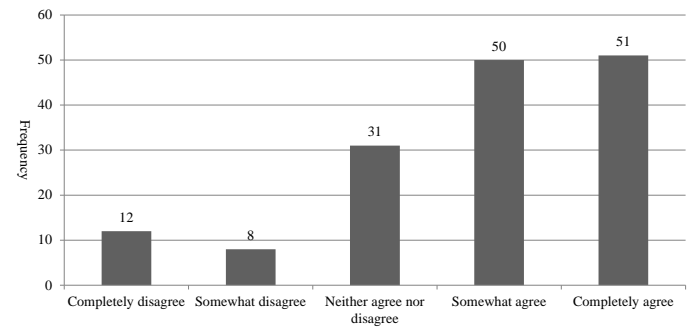

(4) Events Are Space Operation Issue

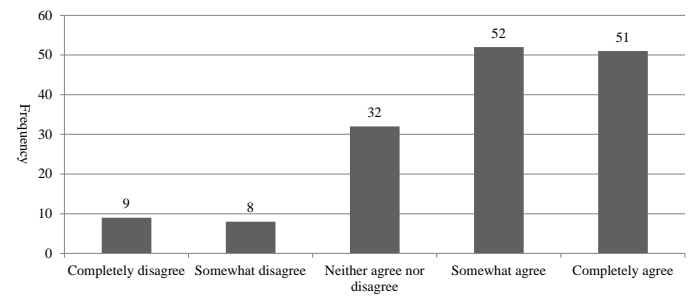

(5) Events Are Planned by the Space Manager

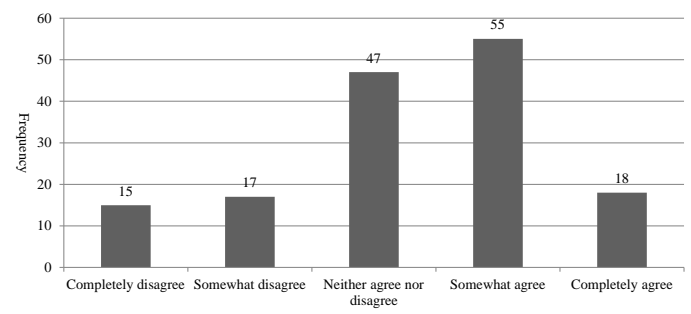

(6) Events Are Proposed by Users

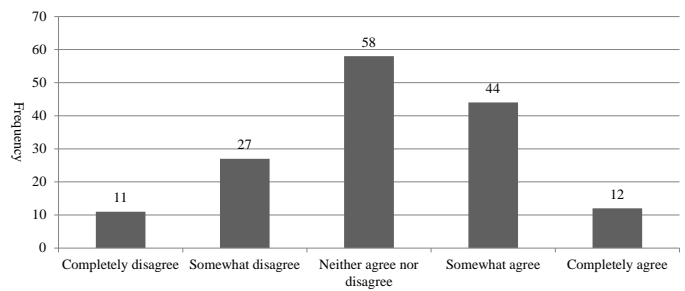

(7) The Space Manager Works as Event Lecturer

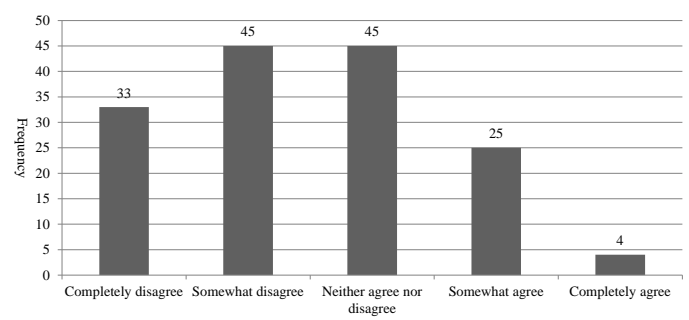

(8) Users Work as Event Lecturer

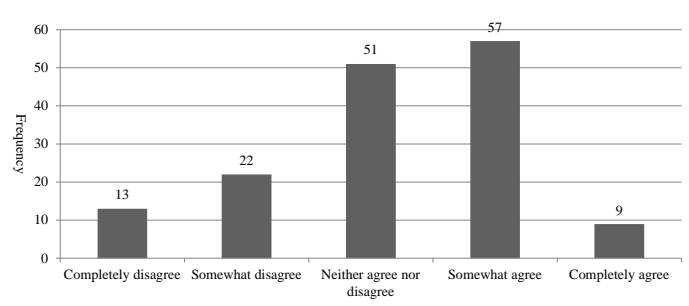

(9) Events Help Increase Users

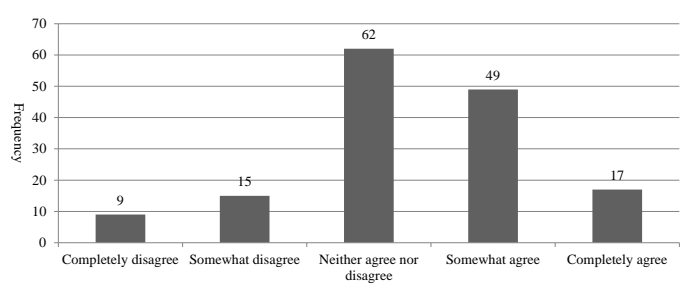

(10) Events Are Important

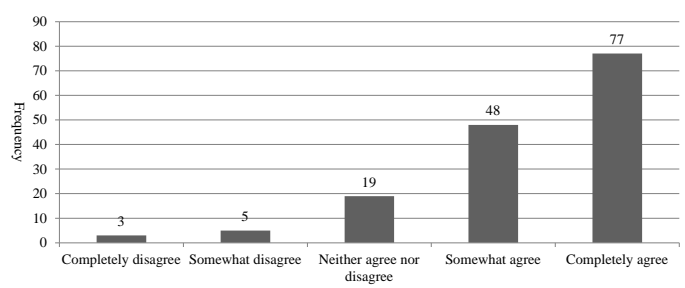

Figure 12: Distribution of Space Manager’s Views on Events

\subsection{Space Users}

We asked questions about users by dividing them into five sections: the user segments (occupations) anticipated at the time of opening and the actual user segments (occupations); 
attributes of users (percentage); number of users; percentage of members and non-members; and the hours of use by members and non-members.

\subsubsection{Anticipated and Actual Users}

First, we examine the user segments anticipated at the time of opening and the actual user segments. The questionnaire asks respondents to choose all that apply from 10 categories: (1)

IT-related, (2) creator/designer-related, (3) Manufacturing-related, (4) community development-related, (5) childcare/women's support-related, (6) building/construction-related, (7) literary/writer-related, (8) sales/marketing-related, (9) clerical-related, and (10) other.

The responses are illustrated in Figure $13 .{ }^{42}$ Concerning the user segments anticipated at the time of opening, those mentioned most frequently were creator/designer-related (114) and IT-related (109). Literary/writer-related (56), product development-related (47), and community development-related (46) were also mentioned frequently. Meanwhile, the actual user segments are, in descending order, IT-related (99), creator/designer-related (92), sales/marketing-related (49), literary/writer-related (46), product development-related (43), and community development-related (43). Thus, the user segments anticipated at the time of opening almost overlap with those that actually use the space.

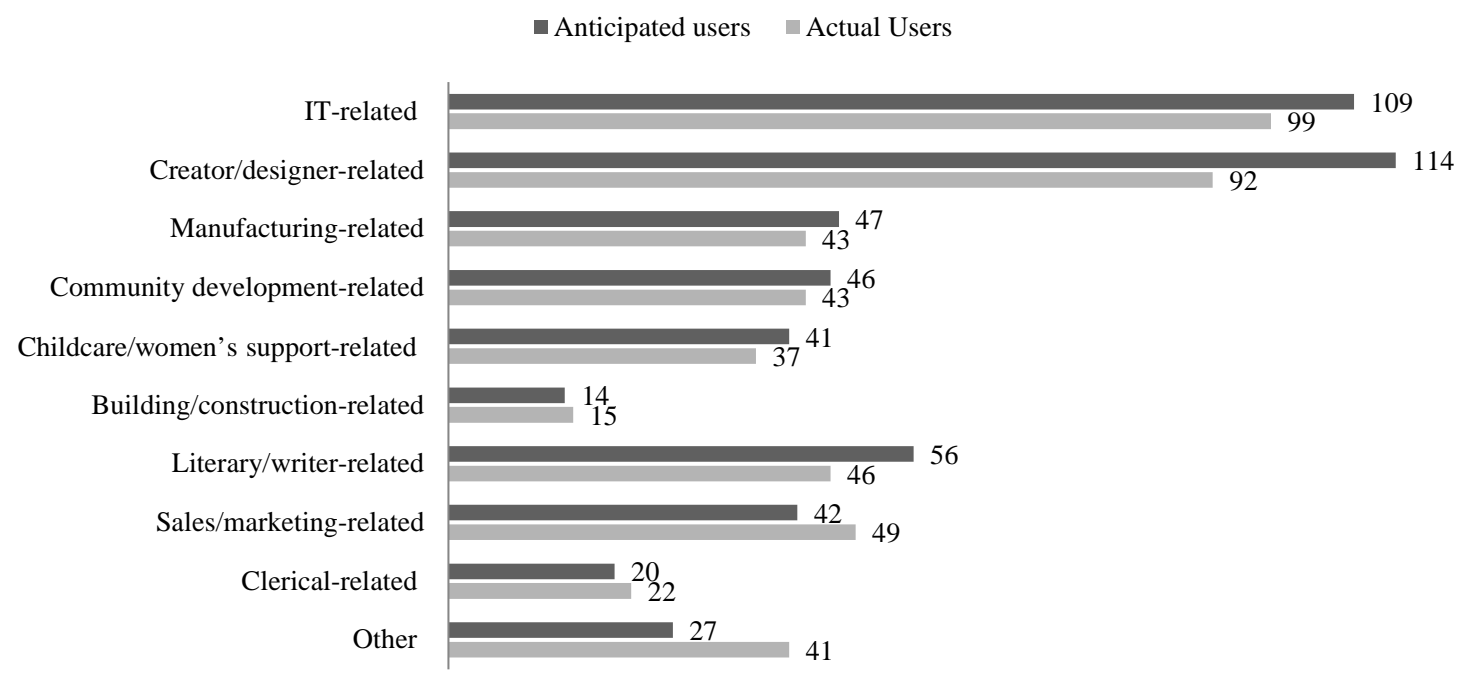

Figure 13: User Segments Anticipated at the Time of Opening and Actual User Groups

\subsubsection{Affiliation, Age, and Gender of Users}

We asked about the affiliations of users—student, employees (e.g., company employee), freelancer, housewife/husband, and other-ensuring that the percentages added up to $100 \%$. As shown in Table 10, $42.8 \%$ are freelancers, $29.7 \%$ are employees, $10.6 \%$ are students, $8.6 \%$ are housewives/husbands, and $8.3 \%$ are "other."

42 Respondents were asked to specify an occupation when they chose "other" in this question as well. We plan to examine what they are in another paper. 
These results confirm that spaces have characteristic user segments. As many users are freelancers, it is not difficult to imagine that some spaces are mostly or almost completely used by freelancers. In fact, there are 21 spaces (13.8\%) where more than $80 \%$ of the users are freelancers. Furthermore, where more than $70 \%$ of the users are in a specific segment, four spaces (2.6\%) are used primarily by students, 13 spaces (8.6\%) are used primarily by employees, and three spaces (2.0\%) are used primarily by housewives/husbands.

Table 10: Affiliations of Users

\begin{tabular}{lrrrrr}
\hline & Students & Employees & Freelancers & $\begin{array}{c}\text { Housewives/ } \\
\text { husbands }\end{array}$ & Others \\
\hline Mean & 10.59 & 29.71 & 42.80 & 8.57 & 8.34 \\
Median & 5 & 30 & 40 & 2 & 0 \\
SD & 15.359 & 23.170 & 27.493 & 15.440 & 19.532 \\
Min. & 0 & 0 & 0 & 0 & 0 \\
Max. & 90 & 95 & 100 & 90 & 100 \\
\hline
\end{tabular}

The responses regarding users' age structures are shown in Figure 14. On average, users under 20 accounted for $5.3 \%$ of the total. Likewise, on average, users in their 20s, 30s, 40s, 50s, and 60s or older accounted for $21.2 \%, 38.4 \%, 22.8 \%, 8.6 \%$, and $3.8 \%$, respectively.

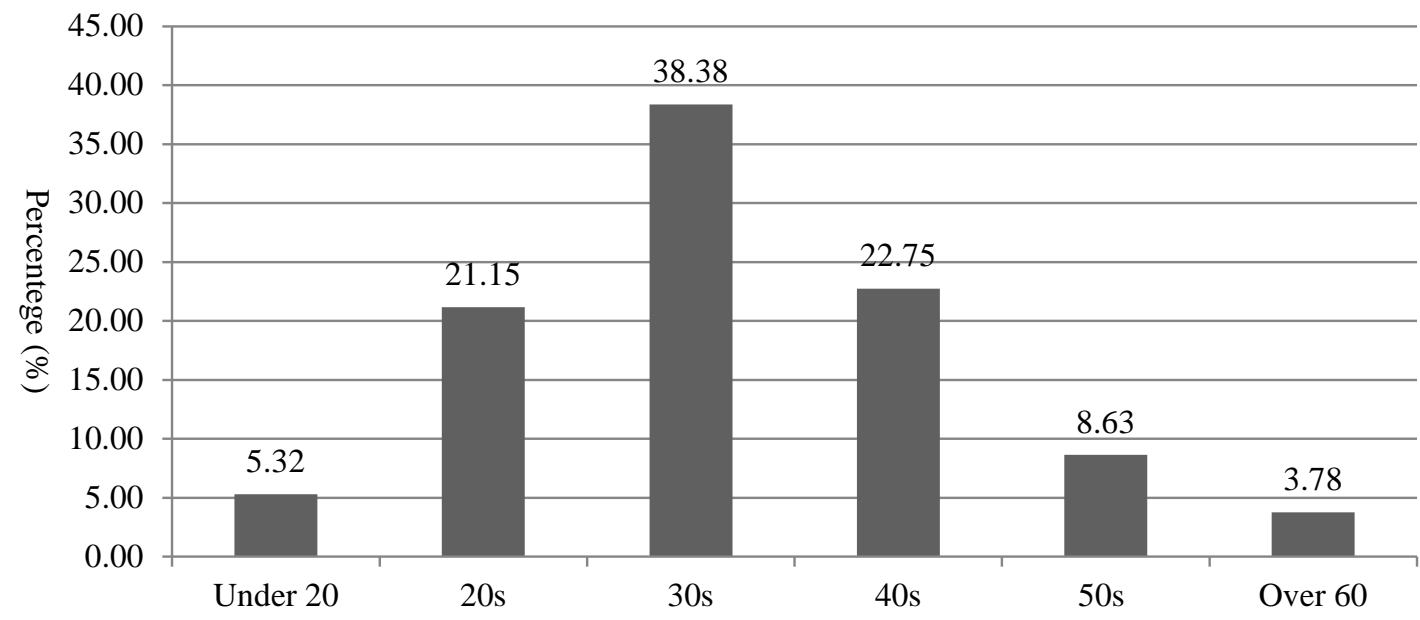

Figure 14: Age Composition of Users

We also asked about users' gender composition. Men account for $59.7 \%$ and women for $40.2 \%$. Figure 15 shows the distribution of the percentage of male users. There were two all-female spaces (1.3\%) and five all-male spaces (3.3\%). 


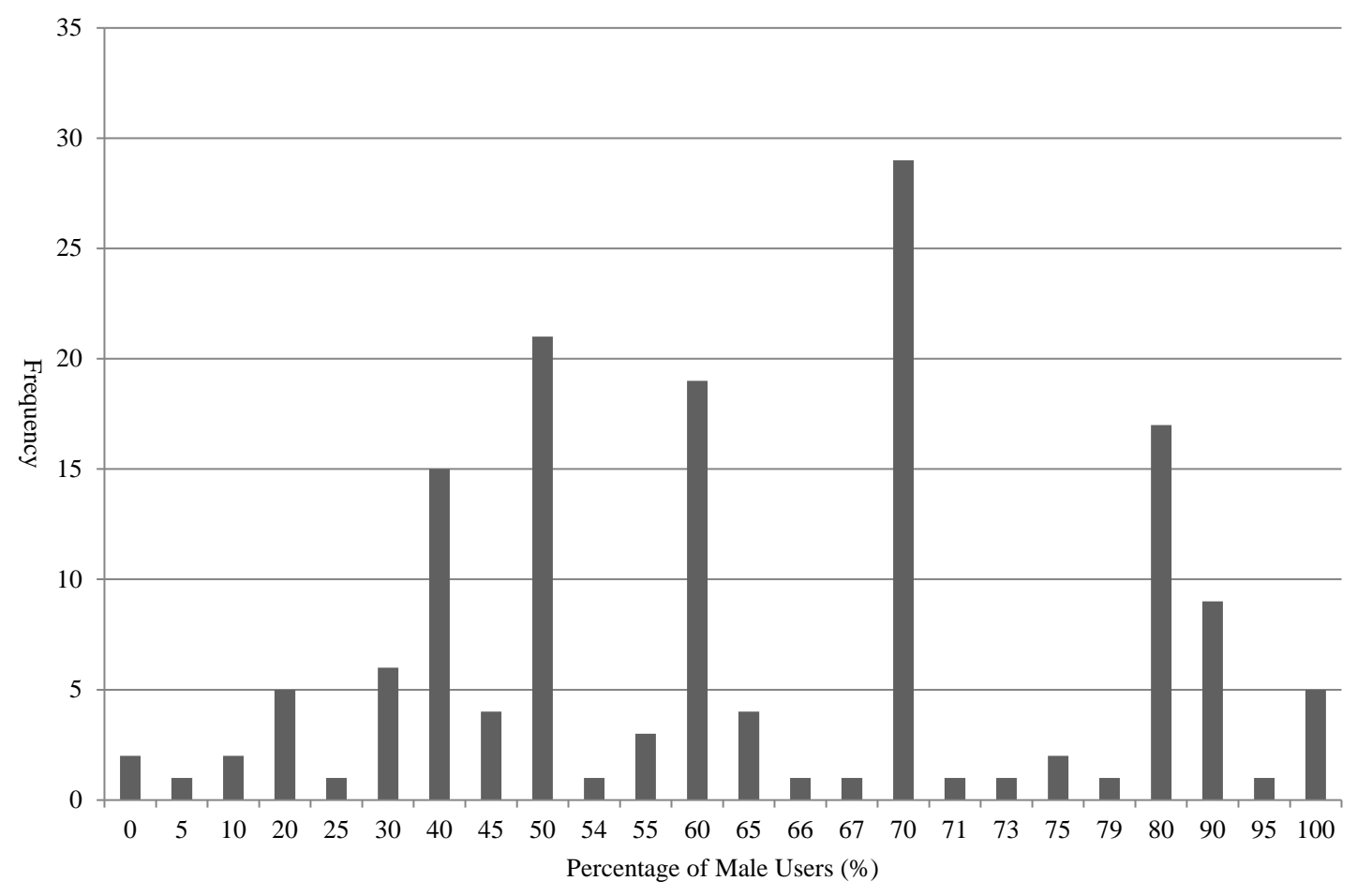

Figure 15: Distribution of the Percentage of Users

\subsubsection{Number of Users}

We obtained responses about the number of users per month and, of these, the number of users whose frequency of use is very high ("the number of heavy users" hereafter). Table 11 shows the number of users per month. The lowest number of users per month was zero (one space) and the highest was 5,000 (one space). Since the difference between the lowest and highest is very large, the average does not seem to be meaningful. Therefore, Figure 16 shows the distribution of the numbers of users per month up to $300 .{ }^{43}$ We see that 22 spaces (14.5\%) had 10 or fewer users and 39 spaces (25.7\%) had 20 or fewer; 94 spaces (61.8\%) had 100 or fewer users; 13 spaces (8.6\%) had 1,000 or more users, and 44 spaces (28.9\%) had 200 or more.

Table 11: Number of Users (month)

\begin{tabular}{lr}
\hline Mean & 265.92 \\
Median & 70 \\
SD & 612.346 \\
Min. & 0 \\
Max. & 5000 \\
\hline
\end{tabular}

\footnotetext{
43 We chose 300 as the maximum value for two reasons: (1) the average number of users was 265, and (2) it would cover a little more than $80 \%$ of respondents.
} 


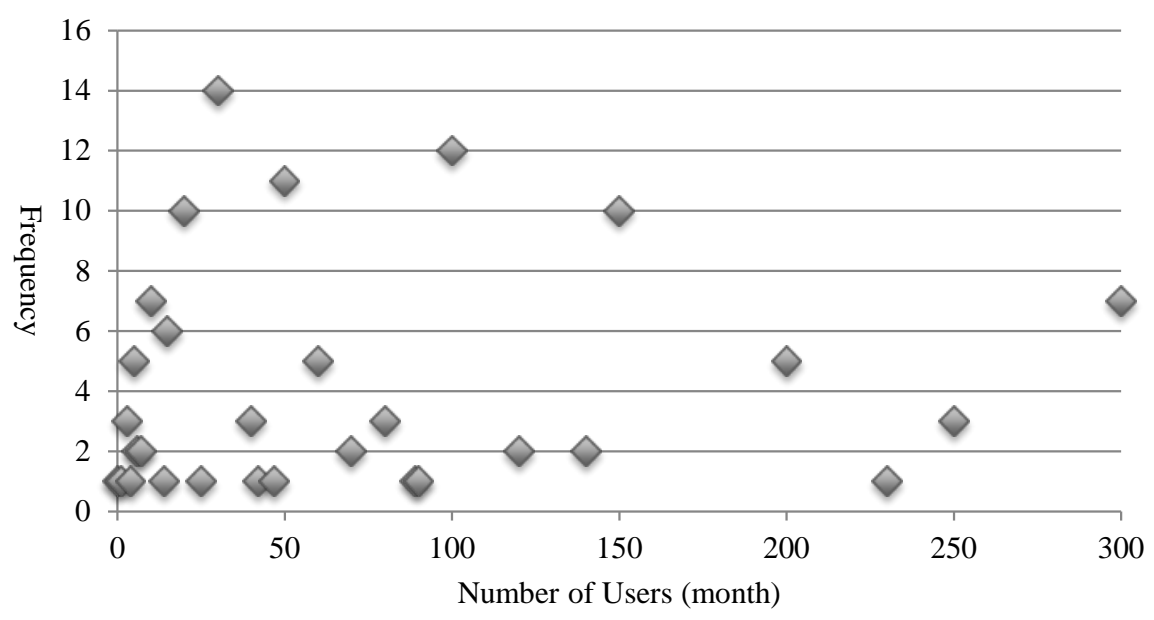

Figure 16: Distribution of the Number of Users (month)

Next, we examine the number of heavy users per month. As shown in Table 12, the lowest number is zero (three spaces) and the highest number is 1,500 (one space). As with the number of users per month, there is little point in reporting the average. Of the total, 88 spaces (57.9\%) had 10 or fewer heavy users and 138 spaces (90.8\%) had 50 or fewer. For reference, we also show in Figure 17 the distribution of the number of users per month, limited to a maximum value of 50 . It tells us that many spaces have around 10 heavy users.

Table 12: Number of Heavy Users (month)

\begin{tabular}{lr}
\hline Mean & 55.17 \\
Median & 10 \\
SD & 183.818 \\
Min. & 0 \\
Max. & 1500 \\
\hline
\end{tabular}

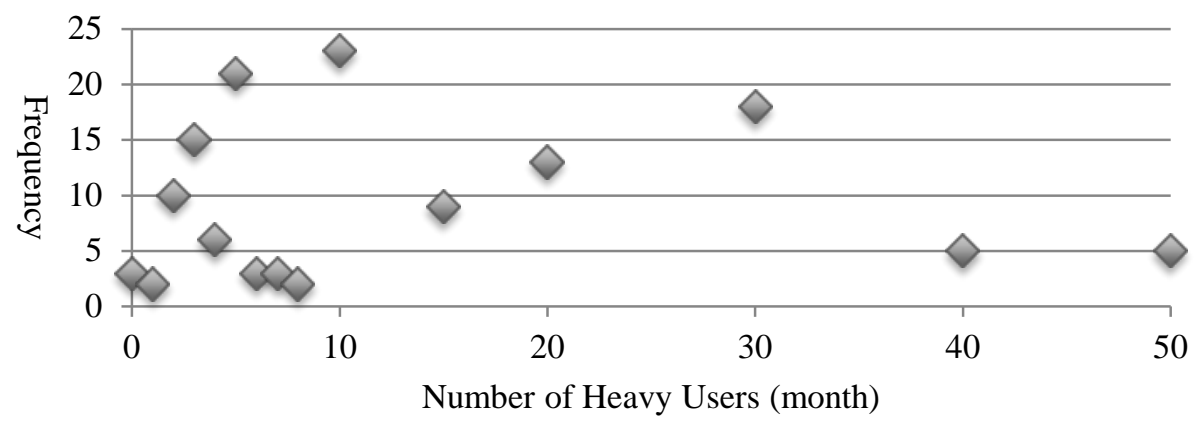

Figure 17: Distribution of the Number of Heavy Users (month) 


\subsubsection{Percentages of Members and Non-members}

We also asked about the percentages of members and non-members. Table 13 shows the descriptive statistics, and Figure 18 shows the distribution. The lowest percentage of members was 0\% (19 spaces), and the highest was 100\% (19 spaces). The average percentages of members and non-members are $46.7 \%$ and 53.3\%, respectively. As shown in Figure 18, while there are 54 spaces (35.5\%) where the percentage of members is $10 \%$ or lower, there are 37 spaces $(24.3 \%)$ where the percentage is $90 \%$ or more. Since the subjects analyzed in this paper are limited to the spaces that allow drop-in usage, such a tendency seems appropriate.

Table 13: Percentages of Members

\begin{tabular}{lr}
\hline Mean & 46.66 \\
Median & 50 \\
SD & 38.906 \\
Min. & 0 \\
Max. & 100 \\
\hline
\end{tabular}

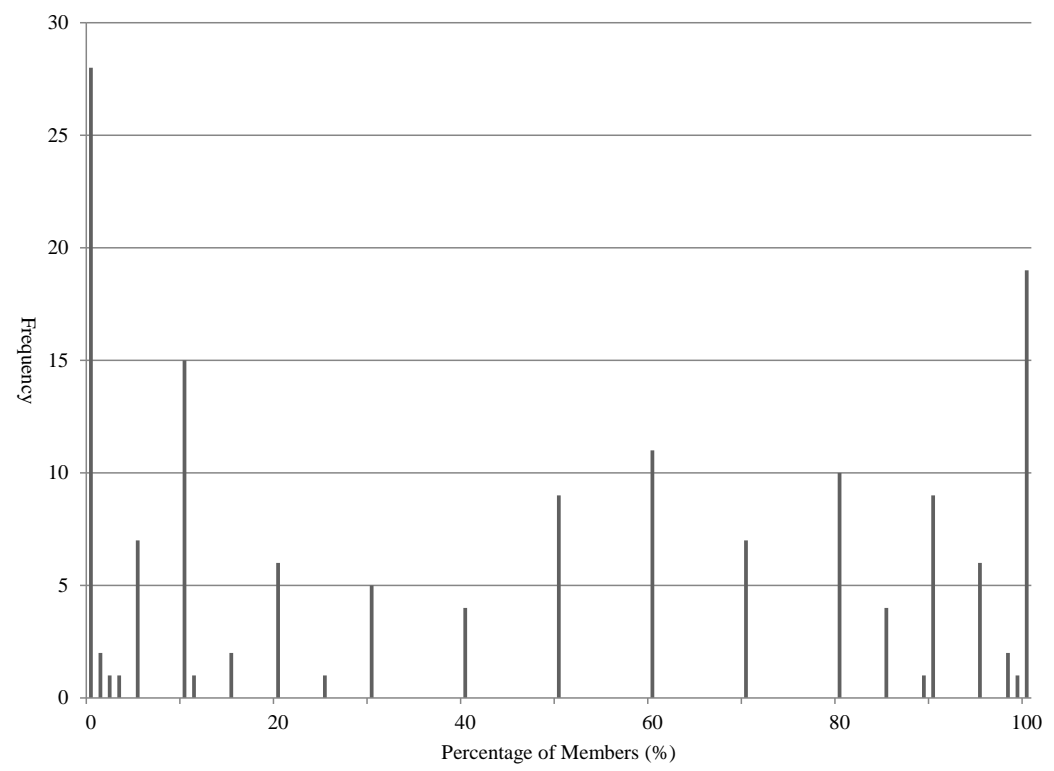

Figure 18: Distribution of the Percentages of Members

\subsubsection{Hours of Use among Members and Non-members}

As shown in Table 14, members use the space for 4.56 hours per day on average. Figure 19 shows the distribution of the number of hours members use the space per day. Members' daily usage is eight hours or less at 141 spaces (92.8\%). Member usage is zero hours at 27 spaces (17.8\%).

The average number of hours non-members use the space per day is 3.14 hours. The distribution of non-members' usage time per day is also shown in Figure 20. Non-members' daily usage is six 
hours or less at 144 spaces (94.7\%). Non-members’ daily usage is zero hours at 21 spaces (13.8\%).

Table 14: Usage Time by Members and Non-members (day)

\begin{tabular}{lrr}
\hline & $\begin{array}{c}\text { Member } \\
\text { (day) }\end{array}$ & $\begin{array}{c}\text { Non-member } \\
\text { (day) }\end{array}$ \\
\hline Mean & 4.56 & 3.14 \\
Median & 5 & 3 \\
SD & 3.023 & 2.054 \\
Min. & 0 & 0 \\
Max. & 13 & 10 \\
\hline
\end{tabular}

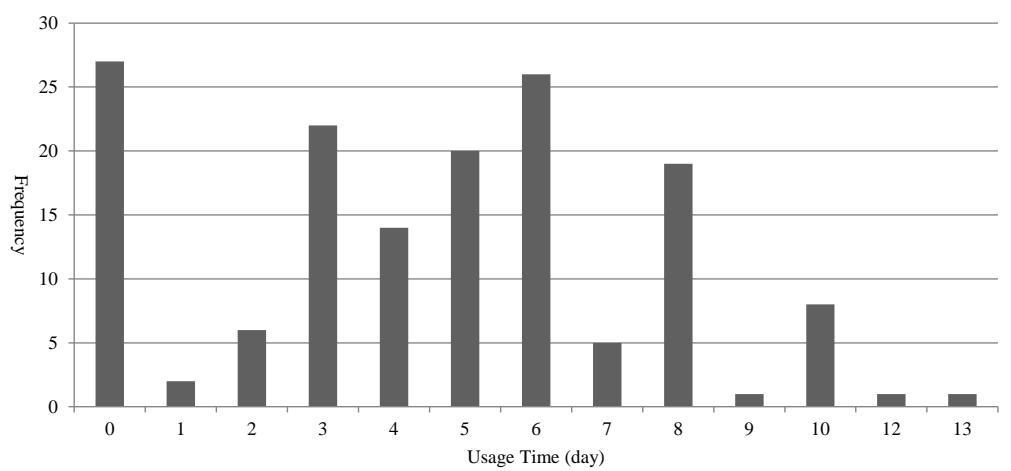

Figure 19: Distribution of Usage Time by Members (day)

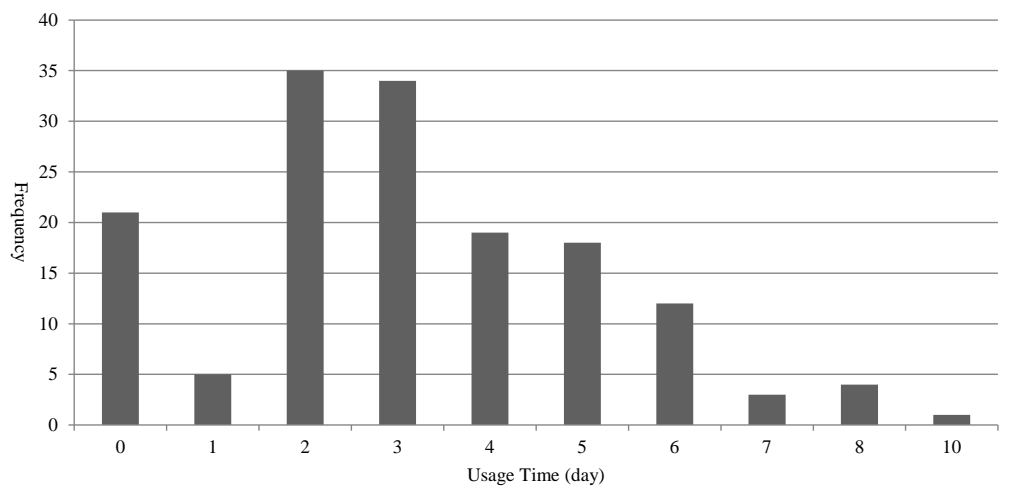

Figure 20: Distribution of Usage Time by Non-members (day)

\subsection{Performance}

\subsubsection{Sales}

As shown in Table 15, responses on monthly sales were obtained from 84 spaces. ${ }^{44}$ The highest is 10 million yen and the lowest is 0 yen. ${ }^{45}$ Figure 21 shows the distribution. There are 13 spaces

44 This question does not require a response; therefore, the number of responses is lower than for other questions. 451 Yen was approximately 0.00951 US Dollar or 0.00726 Euro as of September 3, 2014 when was the last day of our questionnaire survey, according to the Bank of Japan's statistical data about Foreign Exchange (https://www.boj.or.jp/statistics/market/forex/fxdaily/2014/fx140903.pdf). 
(15.5\%) that achieved monthly sales of 1 million yen or more, while 45 spaces (53.6\%) achieved 200,000 yen or less, and 10 spaces (11.9\%) made no sales.

Table 15: Sales (month) ${ }^{46}$

\begin{tabular}{lr}
\hline Mean & 51.42 \\
Median & 20 \\
SD & 117.163 \\
Min. & 0 \\
Max. & 1000 \\
\hline
\end{tabular}

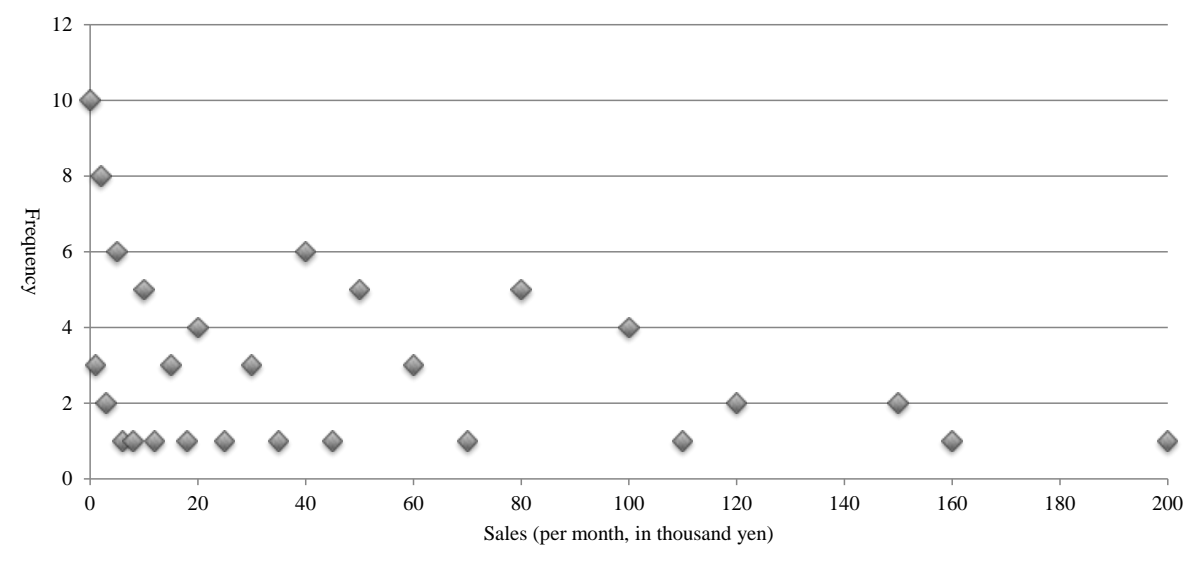

Figure 21: Distribution of Sales (month)

We also asked the percentage of sales accounted for by food and beverage services. As shown in Table 16, the average is $12.0 \%$. However, as might be surmised from the fact that the median is zero, many actually responded that food and beverage services comprise $0 \%$ of sales. This relationship is shown in Figure 22. Food and beverage sales represent $0 \%$ at 89 spaces (58.6\%). Thus, these spaces either do not provide any food or beverage services or provide them free of charge. On the other hand, 18 spaces (11.8\%) said that food and beverage services accounted for more than half of their sales, and 26 spaces (17.1\%) said that food and beverage services accounted for more than $20 \%$.

Table 16: Percentage of Food and Beverage Services in Total Sales

\begin{tabular}{lr}
\hline Mean & 11.97 \\
Median & 0 \\
SD & 25.829 \\
Min. & 0 \\
Max. & 100 \\
\hline
\end{tabular}

46 The sample size is 84 . 


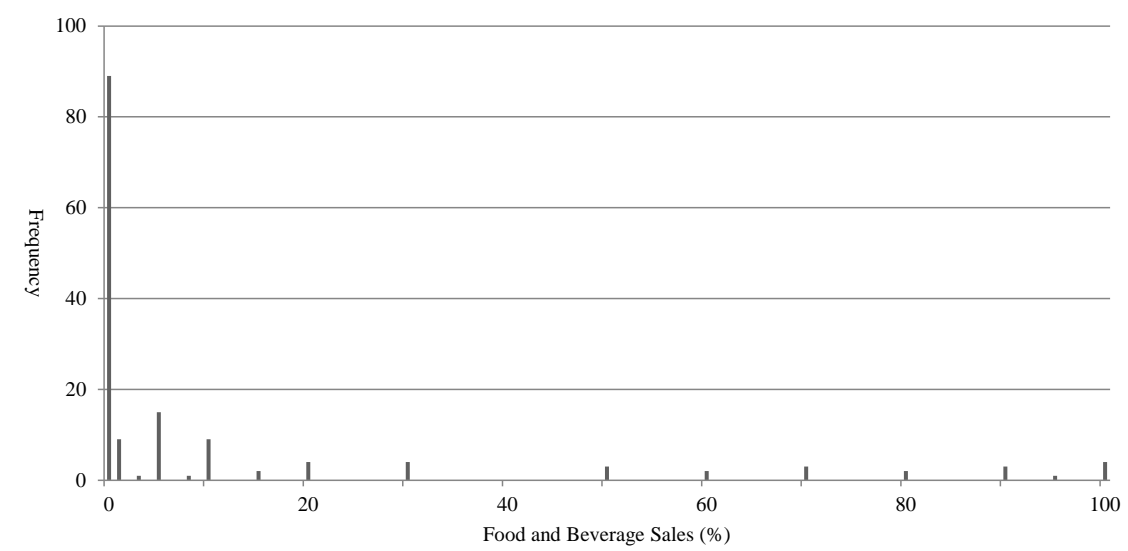

Figure 22: Distribution of the Percentage of Food and Beverage Services in Total Sales

\subsubsection{Sales from Members}

As shown in Table 17, the average percentage of member sales out of overall sales is $56.1 \% .{ }^{47}$ Figure 23 shows the distribution of the percentage of member sales. We see that 22 spaces (14.5\%) generate all sales from members. Meanwhile, 28 spaces (18.4\%) generate no member sales; thus, all sales are generated from non-members. Sixty-seven spaces (44.1\%) generate more than $80 \%$ of all sales from members, and 47 spaces (30.9\%) generate more than $80 \%$ of sales from non-members.

Table 17: Percentage of Member Sales

\begin{tabular}{lr}
\hline Mean & 56.14 \\
Median & 70 \\
SD & 38.735 \\
Min. & 0 \\
Max. & 100 \\
\hline
\end{tabular}

47 This must be interpreted carefully because this is the average of a percentage. 


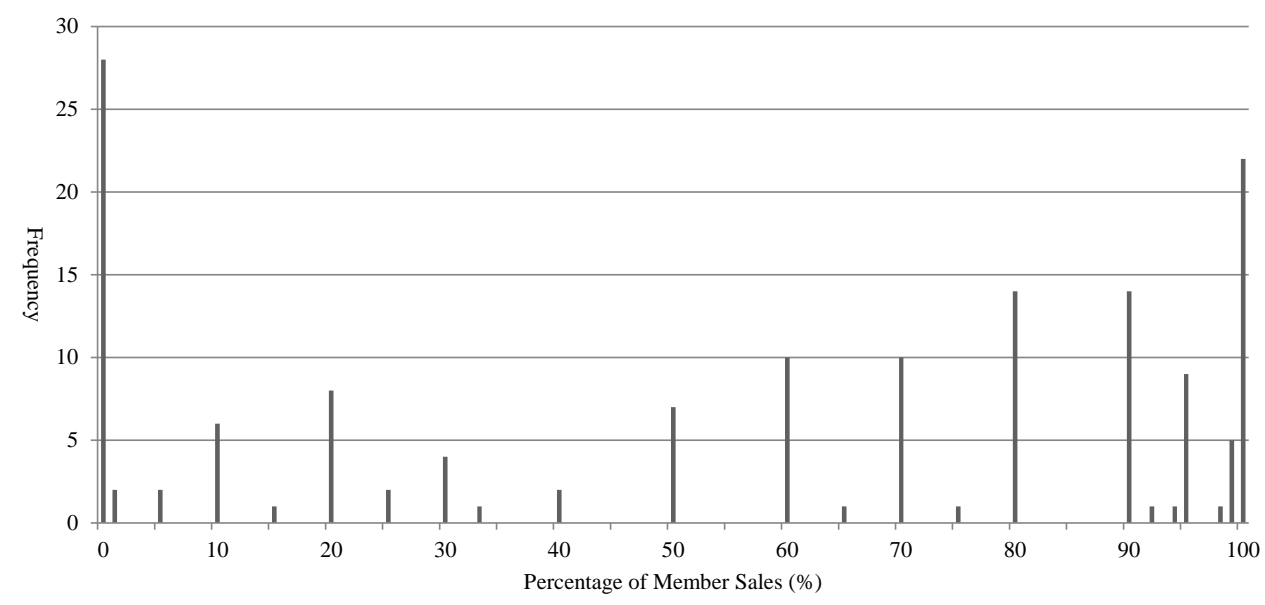

Figure 23: Distribution of the Percentage of Member Sales

\subsubsection{Space Manager's Views on the Current State of Space}

We asked 10 questions regarding space manager's view on the current status of the space. Respondents rated the following 10 items on a five-point scale ( 1 = "completely disagree;" 5 = "completely agree)": (1) "The space manager works to facilitate interactions among users" ("the space manager facilitates user interaction" hereafter); (2) "Users try to interact on their own by exchanging business cards, etc." ("users facilitate own interaction”); (3) "Users use the space because they can get work done" ("the space is used for the purpose of getting work done"); (4) "Users use the space because they hope to interact with the space manager" ("users hope to interact with the space manager"); (5) "Users use the space because they hope to interact with other users" ("users hope to interact with other users"); (6) "New business and services are created through collaboration between users" ("new products and services are created through collaboration”); (7) "New businesses and services are created by individual users" ("new products and services are created by individual users"); (8) "I would like to increase users at the space that I operate" ("want to increase users at the space"); (9) "I'm satisfied with the current state of the space that I operate" ("satisfied with the space's current state"); and (10) "The space generates profits on a non-consolidated basis" ("the space is profitable on a non-consolidated basis").

These 10 items can be grouped into four categories: interactions within the space, purpose for using the space, businesses and services created by space users, and views on the performance of the space. The distribution and mean scores of the responses are shown in Table 18 and Figure 24, respectively.

Concerning interactions within the space (items 1 and 2), space managers are facilitating interactions among users (mean $=3.73$ ). In addition, as shown in Figure 24, space managers at 107 spaces (70.4\%) are facilitating interactions among users. 82 space managers $(54.0 \%)$ believe that users facilitate their own interactions.

Concerning the purpose of using the space (items 3,4 , and 5), space managers believe that users are using the space because they can get work done (mean $=3.72$ ). However, it is suggested that users are not necessarily hoping to interact with other users or the space manager. 
We also asked space managers about new products and services created by their users (items 6 and 7). Although the mean score is not high, examining the distribution reveals that half of the space managers said that new products and services are being created through collaboration between users as well as by individual users, albeit with a certain level of difference. Thus, there are spaces where new products and services are created by users, while there are others where that is not the case.

We asked about space manager's view on the performance of the space as well (items 8, 9, and 10). The results show that a space manager is not necessarily satisfied with his/her space's current state $($ mean $=2.26)$. Negative views on this item add up to 97 spaces $(63.8 \%){ }^{48}$ Many space managers also said that their spaces are not profitable on a non-consolidated basis (mean $=2.28$ ). Many space managers want to increase the number of users (mean $=4.43$ ). These response trends suggest that the biggest issue for a space manager is that his/her space is not profitable on a non-consolidated basis.

Table 18: Space Manager's View on the Current State of the Space

\begin{tabular}{lrr}
\hline & Mean & SD \\
\hline (1) The space manager facilitates user interaction & 3.73 & 1.223 \\
(2) Users facilitate own interaction & 3.41 & 1.198 \\
(3) The space is used for the purpose of getting work done & 3.72 & 0.945 \\
(4) Users hope to interact with the space manager & 3.38 & 0.919 \\
(5) Users hope to interact with other users & 3.51 & 1.029 \\
(6) New products and services are created through collaboration & 3.43 & 1.120 \\
(7) New products and services are created by individual users & 3.32 & 1.089 \\
(8) Want to increase users of the space & 4.43 & 0.850 \\
(9) Satisfied with the space's current state & 2.26 & 1.078 \\
(10) The space is profitable on a non-consolidated basis & 2.28 & 1.303 \\
\hline
\end{tabular}

48 The sum of "Completely disagree” and "Somewhat disagree." 
(1) The Space Manager Facilitates User Interaction

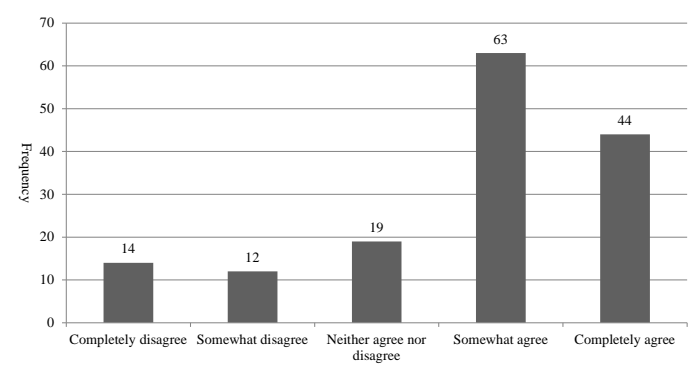

(2) Users Facilitate Own Interaction

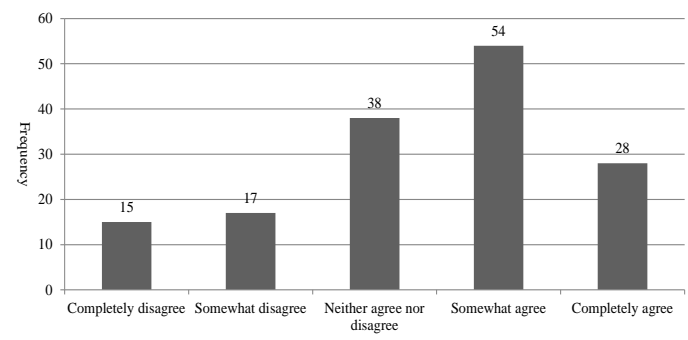

(3) The Space Is Used for the Purpose of Getting Work Done

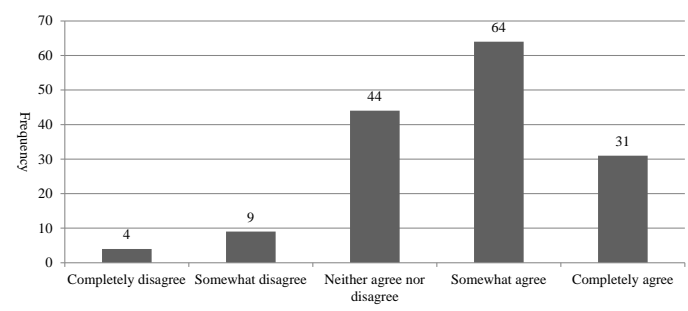

(4) Users Hope to Interact with the Space Manager

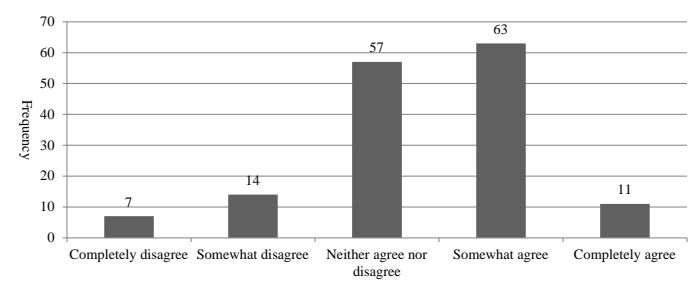

(5) Users Hope to Interact with Other Users

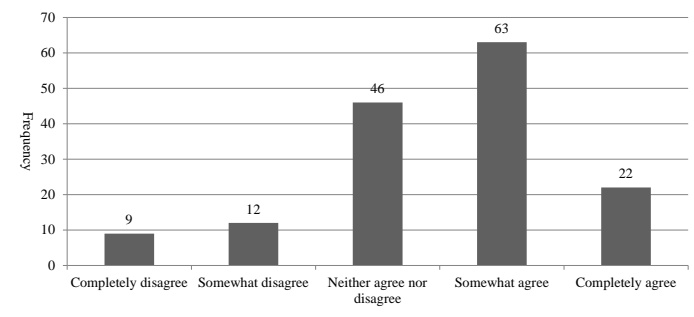

(6) New Products \& Services Are Created Through Collaboration

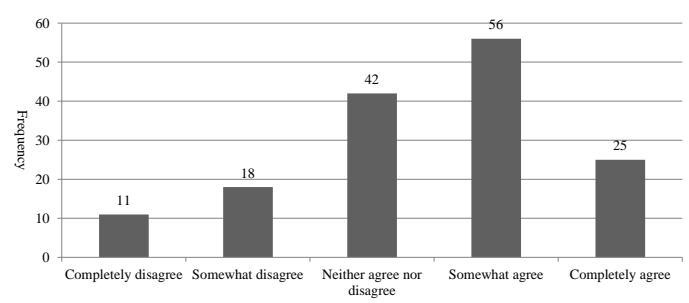

(7) New Products \& Services Are Created by Individual Users

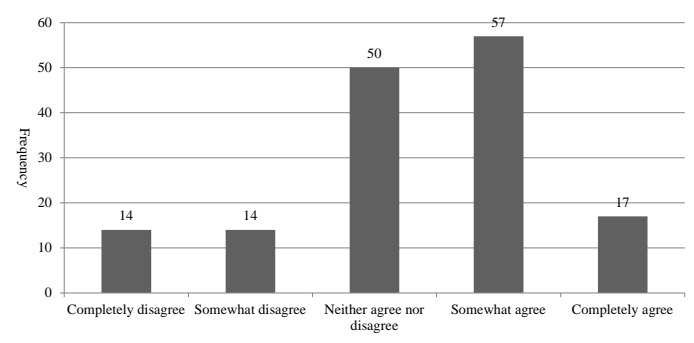

(8) Want to Increase Users of the Space

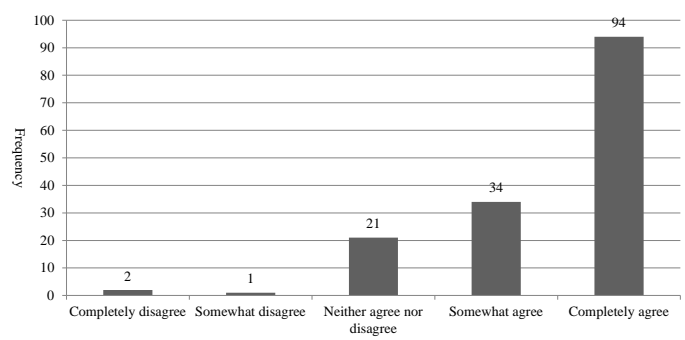

(9) Satisfied with the Space's Current State

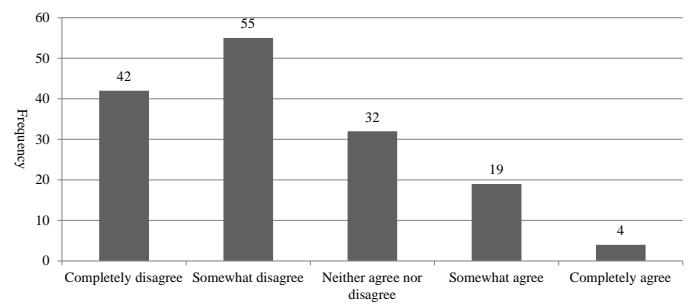

(10) The Space Is Profitable on a Non-Consolidated Basis

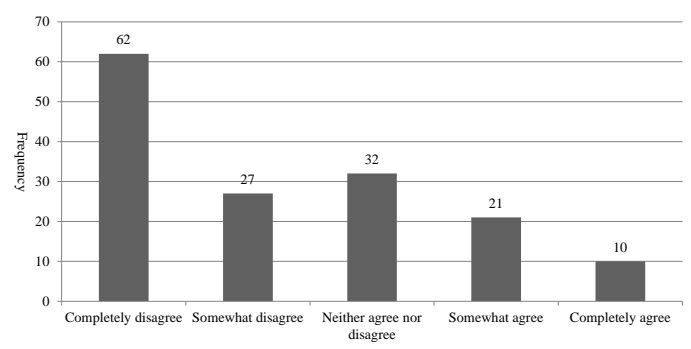

Figure 24: Distribution of Space Manager's View on the Current State of the Space 


\section{Discussion}

Table 19 presents the main findings on matters that we have examined in this paper so far. In what follows, we will weigh the findings in this paper against the findings presented in the previous studies such as the GCS and Hanibuchi (2014) by dividing them into six parts just as in the examinations we have done so far.

Table 19: Main findings of this Paper

\begin{tabular}{|c|c|}
\hline & Main findings \\
\hline Facility & $\begin{array}{l}\text { - } \quad \text { The floor size of most (close to } 70 \% \text { ) spaces is } 100 \text { square meters or less. } \\
\text { - } \quad \text { Close to half of the spaces have an open floor (i.e., are not divided by partitions). }\end{array}$ \\
\hline $\begin{array}{l}\text { Management } \\
\text { Organization }\end{array}$ & $\begin{array}{l}\text { - } \\
\text { - } \\
\text { - } \\
\text { - } \\
\text { - } \\
\text { - } \\
\text { - } \\
\text { Many (any (a little over } 60 \% \text { ) spaces have an IT-related or a creative/design-related area of business. } \\
\text { Most (a little over } 70 \% \text { ) have one or two businesses other than the space business. } \\
\text { The management experience among almost all (a little over } 90 \% \text { ) space managers is three years or less. }\end{array}$ \\
\hline Business & $\begin{array}{l}\text { - While other spaces are not viewed as competitors, a variety of businesses (such as shared offices) are } \\
\text { viewed as competitors. } \\
\text { - } \quad \text { Many space managers consider community formation in spaces as important. } \\
\text { The profitability of the space business on a non-consolidated basis is not considered very important. }\end{array}$ \\
\hline Activity & $\begin{array}{l}\text { - } \\
\text { - } \quad \text { Spacest (close to } 70 \% \text { ) spaces hold a different type of event once a week. } \\
\text { where that in not the case. }\end{array}$ \\
\hline Space Users & $\begin{array}{l}\text { - } \\
\text { - } \\
\text { - Whe user segments anticipated prior to opening the space and the actual user segments mostly overlap. } \\
\text { A little over } 60 \% \text { of users are in their } 30 \text { s or } 40 \text { s, which corresponds to the age group of space } \\
\text { managers. } \\
\text { - The number of users per month is } 100 \text { or fewer at many (a little over } 60 \% \text { ) spaces. } \\
\text { Spaces tend to fall into two groups: those with a very high percentage of members (a little over } 20 \% \text { ) } \\
\text { and those with a very low percentage (a little over } 30 \% \text { ). }\end{array}$ \\
\hline Performance & 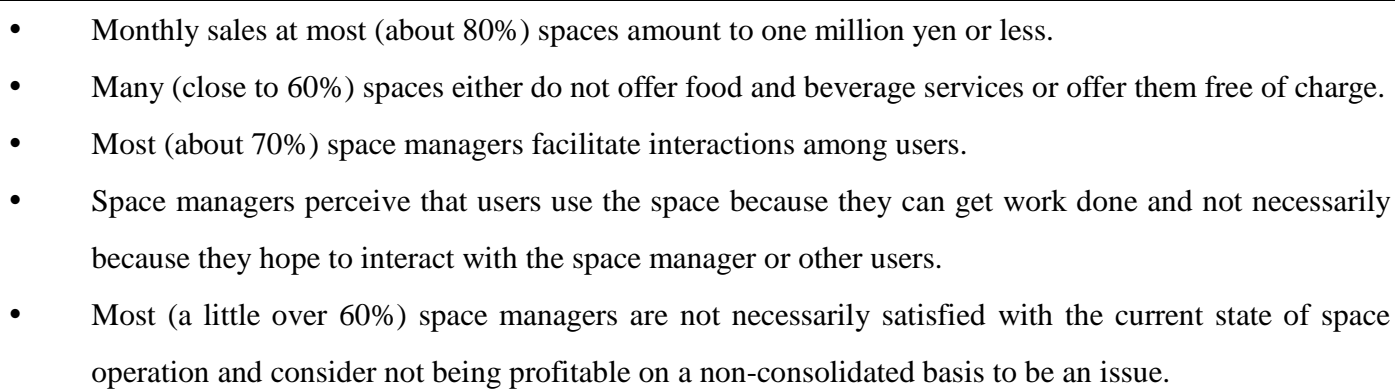 \\
\hline
\end{tabular}




\subsection{Examination of Facility}

A comparison of the number of seats is shown in Figure 25. According to the GCS, the average number of desks trends from 38 to 40 and then to 41 between the first and third surveys. ${ }^{49}$ The number was 33.9 seats in this study. Although the number of seats at coworking spaces in Japan found in this paper is slightly lower than the average in the GCS, the trends in the number of seats seem almost the same in Japan and overseas.

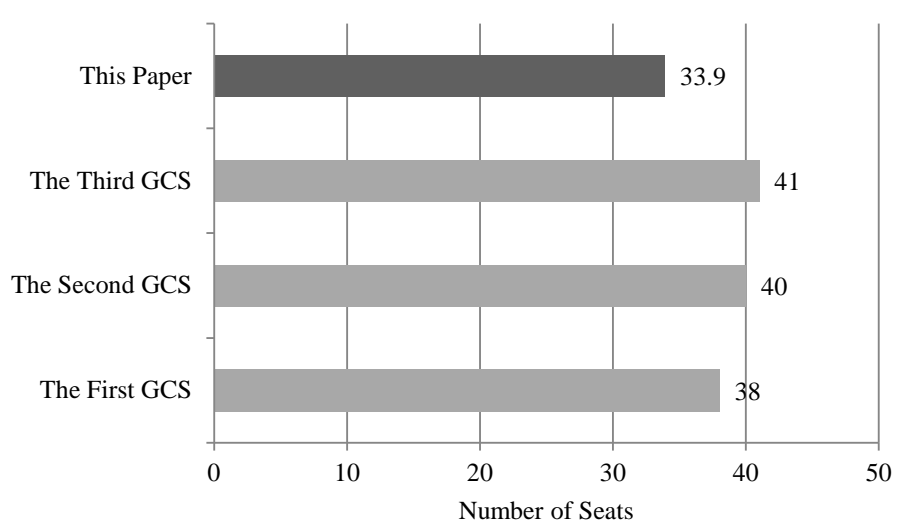

Figure 25: Comparison of the Number of Seats

\subsection{Examination of Management Organization}

There are three comparison items related to management organization: the number of staff, degree of specialization, and length of time the space has been in operation. We will examine them in order. In the second GCS, the number of founding members when the space opened is 2.8 . Despite the potential problem in directly using this figure as the number of staff, we will compare them as a proxy variable. Our study shows that the number of full-time staff involved in operating a space is 2.63. Therefore, the number of main staff required to operate a space is similar in Japan and overseas.

In the second GCS, 74\% of space managers have some sort of second jobs, with businesses dedicated to space operation in the minority. The same tendency is seen in this paper: of the 149 spaces that answered the question on the positioning of the space business, only 14 (9.4\%) are dedicated to operating the space.

Although the time spent in business is also measured by an indicator different from that used in the GCS and the survey periods are different, they seem comparable. The average period in business according to the second GCS is 18 months. In addition, 50\% of the spaces opened no more than 12 months ago. Since we did not directly ask about time spent in business, we will use the space manager's experience in operating a space as a proxy variable. ${ }^{50}$ The average management

49 The GCS counts the number of desks, which seems equivalent to counting the number of seats, as used in this paper.

50 The space manager's experience in operating a space was used here because we determined that the management experience of the main space managers is quite similar to the period in business based on the fact that, at the time of study, it had been about four years since the opening of the first facility to be billed as a coworking space in Japan, 
experience is 19.5 months, and the number of spaces where the space manager's management experience is less than 12 months is 43 (28.3\%). Thus, the average periods in business are very similar.

\subsection{Examination of Business Strategy}

Concerning strategy, we will examine competitor for spaces and relationships with other spaces. Since the second GCS asks where the space users came from (i.e., their prior workplace) while we ask who the space managers consider to be competitors, interpretation requires caution; however, a comparison is possible. Based on the GCS, it can be inferred that the home/SOHO is a competitor. In this paper, space managers appear to perceive a variety of competitors. Among these, rental/shared offices, cafes/casual restaurants, and homes/SOHOs were mentioned most frequently. Thus, the difference from the GCS is that cafes and casual restaurants are cited as competitors.

Next, we examine the relationship with other spaces. While direct comparison is difficult here as well because the questions are different, the following points are worth noting. The GCS shows that $83 \%$ of the spaces surveyed interact with other spaces and that $10 \%$ of the spaces do not interact with other spaces. In this study, through question items about cooperation policy (rather than interaction) on a five-point scale, it was shown that spaces do not cooperate significantly with neighboring spaces or distant spaces. Even when adding the number of responses for 4 ("somewhat agree”) and 5 (“completely agree”), the spaces that cooperate with neighboring or distant spaces still total 50 (32.9\%) and 55 (36.2\%), respectively. Different trends in the relationship with other spaces are observable in Japan and overseas.

\subsection{Examination of Activity}

The results of the GCS and of this paper concerning events can be directly compared. As shown in Figure 26, events are held 4.5 times per month on average according to the second GCS, while events are held 5.68 times on average in this study. The second GCS also shows that $15 \%$ of the spaces hold 10 or more events per month and that $21 \%$ of the spaces hold an average of two events per month. In this paper, on the other hand, 38 spaces (25.0\%) hold 10 or more events per month, while 23 spaces (15.1\%) hold two events per month. In terms of monthly average, those surveyed in this paper hold events more frequently. The percentage of spaces that hold 10 or more events per month is also high. However, this difference may be negligible.

and it is a relatively new business. 


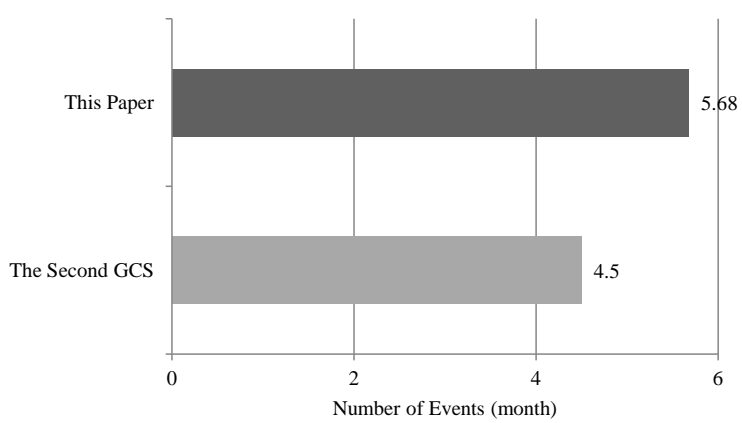

Figure 26: Comparison of the Number of Events (month)

\subsection{Examination of Space Users}

Three user variables - age, gender, and occupation — can be compared. In the first GCS, users under 40 and under 30 account for $78 \%$ and $41 \%$, respectively. In this paper, users under 40 and under 30 account for $64.8 \%$ and $26.5 \%$, respectively. More users are under 30 in the GCS. ${ }^{51}$

In the GCS, two thirds of the users are male. In this paper, $60 \%$ are male. Unlike the GCS, however, we asked for a user breakdown; therefore, interpretation requires caution. ${ }^{52}$

Regarding occupation, Figure 27 shows a comparison. In the first GCS, 54\% of users are freelancers, $20 \%$ are entrepreneurs who employ others, and 20\% are permanent employees (most working at a company with fewer than five employees. In this paper, $42.8 \%$ are freelancers, and $29.7 \%$ are employees. Considering the results of the GCS and reading "regular employees" as our "employees," the percentage of employees among users is high. However, this percentage also requires interpretive caution. ${ }^{53}$

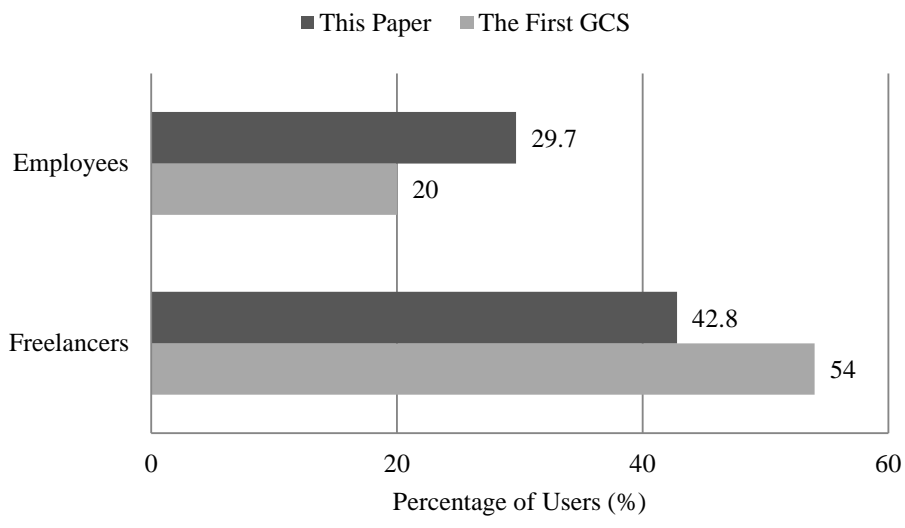

Figure 27: Comparison of Users’ Occupations

\footnotetext{
${ }^{51}$ In Hanibuchi (2014), 29.2\% are in their 20s, 46.4\% are in their 30s, and 17.1\% are in their 40s. Therefore, we can say that the distribution of user ages is similar to that in this paper.

52 In Hanibuchi (2014), 82.8\% of users are male, significantly different from the results in this paper and the GCS.

53 In Hanibuchi (2014), 46.9\% are self-employed and freelancers, $19.4 \%$ are company and government employees, and $19.4 \%$ are executive officers. Almost the same freelancer percentage is observed in this paper.
} 


\subsection{Examination of Performance}

Regarding performance, we examine whether spaces are generating profits on a non-consolidated basis. As shown in Figure 28, close to half (40\%) generate profits in the space business in the second GCS, while this paper shows that only 31 spaces (20.4\%) are profitable on a non-consolidated basis. ${ }^{54}$

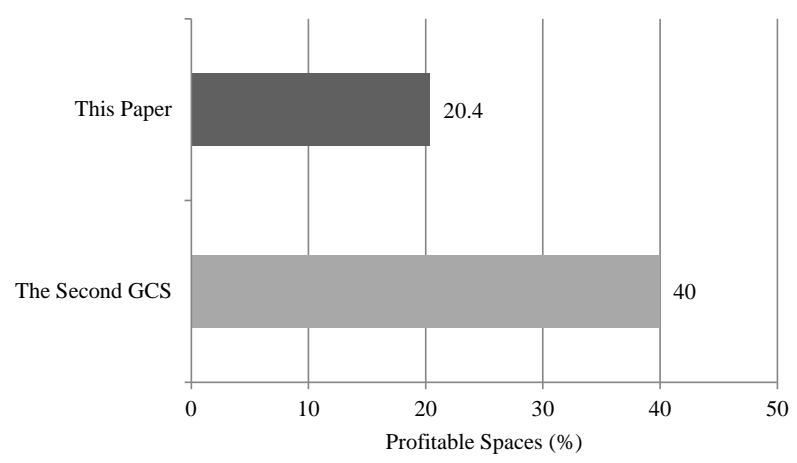

Figure 28: Percentage of Spaces that are Profitable on a Non-consolidated Basis

Next, we examine the percentage of unprofitable spaces by number of seats. As shown in Figure 29 , in the second GCS, more than half (56\%) of the spaces with fewer than 10 seats are unprofitable. Meanwhile, of the 14 spaces with fewer than 10 seats surveyed in this paper, only two spaces (14.3\%) are profitable on a non-consolidated basis, while 12 spaces (85.7\%) are unprofitable. ${ }^{55}$ Since the sample size is 12 (and thus quite small), interpreting the data requires caution. In addition, of the spaces with 50 or more seats, $70 \%$ are profitable and $20 \%$ are unprofitable in the second GCS. In this paper, 30 spaces have 50 or more seats, of which 13 (43.3\%) are profitable and 10 (33.3\%) unprofitable.

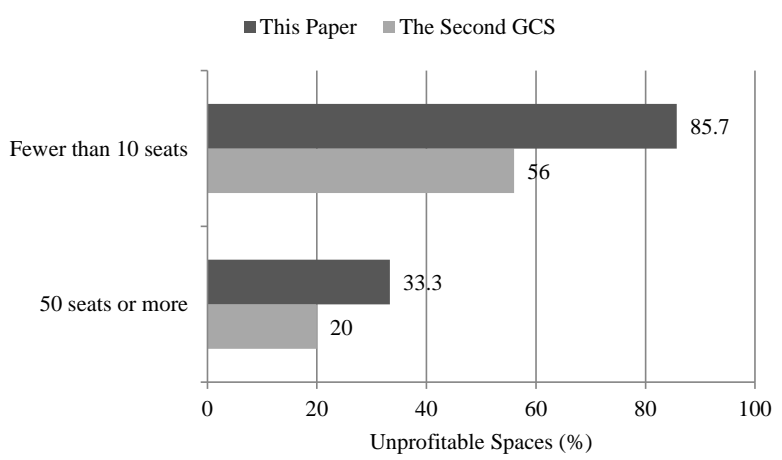

Figure 29: Percentage of Unprofitable Spaces by Number of Seats

\footnotetext{
54 The respondents who said "Somewhat agree" or "Completely agree" to the question item "The space is profitable on a non-consolidated basis" explained in Section 4.6.3 add up to 31 spaces.

55 The spaces that indicated 1 ("Completely disagree") or 2 ("Somewhat disagree”) to the question item "The space is profitable on a non-consolidated basis" shown in (10) of Figure 24 were assumed to be unprofitable. They add up to 12 spaces.
} 


\section{Conclusion}

In this paper, we have shown the results of descriptive statistics on the current status of coworking spaces in Japan especially from the viewpoint of space managers by dividing them into six parts. Very few empirical studies have been conducted on coworking or coworking spaces, and very few studies have sought an overall picture of this phenomenon in a given country. Therefore, we consider that the findings in this paper, based on data from 152 spaces in Japan, are significant. However, several issues remain, which can be divided into two types: those related to the way of designing survey and the way of analyzing data.

One issue of the former type is to conduct a user survey. The GCS and Hanibuchi (2014), for example, collect and analyze data on users. Comprehensively understanding the phenomenon of coworking requires a survey not only of space managers but also of users. It would also be useful to conduct a panel survey on space operation and compare it with the findings in the GCS.

Concerning the way of analyzing data, this study uses only descriptive statistics. The data in this paper should be used to perform, for example, correlation and regression analyses in order to gain a comprehensive understanding of the operation of the coworking space and a way of working called coworking.

Acknowledgment: The results in this paper form part of research supported by Grant-in-Aid for Scientific Research (B; JSPS KAKENHI Grant Number 25285110) and Grant-in-Aid for Scientific Research (C; JSPS KAKENHI Grant Numbers 26380450 and 15K03596). We would like to take this opportunity to express our gratitude. 


\section{References}

Abe, Tomokazu, and Tadashi Uda (2015). “A Correlation Analysis of the Questionnaire Survey on Coworking Spaces in Japan," The Economic Studies, Hokkaido University Collection of Scholarly and Academic Papers, 65 (1), 97-135 (in Japanese).

Arimoto, Masaaki, Naoto Matsumoto, Yuji Matsumoto, Nagisa Kidosaki, and Ryusuke Naka (2012). "A Study on Workplace for Coworking (Part 1)," Summaries of Technical Papers of Annual Meeting, Architectural Institute of Japan, 331-332 (in Japanese).

Hanibuchi, Tomoya (2014). FY 2013 Special Research Report: The Current State and Potential of Collaborative Workspace in Urban Areas, Nagoya Urban Institute, Nagoya Urban Development Public Corporation (in Japanese).

Kobayashi, Asami (2011). “The world’s Unique Membership Library as Coworking Space for Institutionally-Independent Individuals: The Academyhills Roppongi Library,” Journal of Information Processing and Management, 54 (9), 545-554 (in Japanese).

Koizumi, Masanobu, Koichi Ikeda, and Masashige Motoe (2013). "A Report on the Activity in the Space for Personal Fabrication (Part 2): Characteristics of the Facility in the United States and the Netherlands,” Journal of Japan Society for Office Studies, 5 (1), 66-71 (in Japanese).

Koizumi, Masanobu, Koichi Ikeda, and Masashige Motoe (2014). "A Report on the Activity in the Space for Personal Fabrication (Part 3): Features and Issues of Shared Fabrication Spaces in Japan,” Journal of Japan Society for Office Studies, 6 (2), 37-43 (in Japanese).

Koizumi, Masanobu, Yoshitake Sasai, Koichi Ikeda, and Masashige Motoe (2012). “A Report on the Activity in the Space for Personal-Fabrication,” Journal of Japan Society for Office Studies, 4 (1), 64-70 (in Japanese).

Nakamura, Masaaki (2013). "Current Status and Strategies for the Coworking Space Business," Journal of the faculty of Management (Chukyo University), 22 (1 \& 2), 59-74 (in Japanese).

Spinuzzi, Clay (2012). "Working Alone Together: Coworking as Emergent Collaborative Activity,” Journal of Business and Technical Communication, 26 (4), 399-441.

Uda, Tadashi (2013). "What is Coworking? A Theoretical Study on the Concept of Coworking," Graduate School of Economics and Business Administration, Hokkaido University, Discussion Paper, Series A, No. 265

Watanabe, Shuji, Naoto Matsumoto, Yuji Matsumoto, Nagisa Kidosaki, and Ryusuke Naka (2012). “A Study on Workplace for Coworking (Part 2)," Summaries of Technical Papers of Annual Meeting, Architectural Institute of Japan, 333-334 (in Japanese). 